\title{
Modular simulation model for falling film evaporators with novel approach to manage dominant time-varying transport delays
}

\author{
Christian Schwaer ${ }^{\mathrm{a}, \mathrm{b}, *}$, Julian Hofmann ${ }^{\mathrm{b}}$, Michael Mühlpfordt ${ }^{\mathrm{c}}$, Andreas Frank ${ }^{\mathrm{c}}$, Lutz Gröll ${ }^{\mathrm{b}}$ \\ a Automation and Control Institute (ACIN), TU Wien, Gusshausstrasse 27-29, Vienna 1040, Austria \\ ${ }^{\mathrm{b}}$ Institute of Applied Informatics, Karlsruhe Institute of Technology, Hermann-von-Helmholtz-Platz 1, Eggenstein-Leopoldshafen 76344, Germany \\ ${ }^{c}$ GEA Wiegand GmbH, Am Hardtwald 1, Ettlingen 76275, Germany
}

Keywords:

Falling film evaporator

Mechanical vapor recompression

Modular simulation model

Time-varying transport delay

\begin{abstract}
A B S T R A C T
A modular simulation model of the evaporator is developed by dividing it into design-independent subsystems. By introducing this modularity, numerous different evaporator designs, system parameters, operating points or control concepts can be configured and simulated. The plant operation or design can therefore be easily tested and costs for staff and experiments can be particularly reduced.

A large challenge to create valid simulation tools consists of modeling the product transport within connecting pipes and during the evaporation process within the tubes, which in a dynamic process both lead to time-varying delays. As previously published models only include constant transport delays, they are disadvantageous to simulate real plant operation. In order to improve the simulation validity, a detailed dynamic full plant model is developed, which is able to illustrate dominant time-varying transport delays. A comparison with measured data of an existing falling film evaporator shows the validity of the proposed model.
\end{abstract}

\section{Introduction}

Falling film evaporators (FFEs) are industrial heat exchangers to concentrate solutions, suspensions or emulsions and are widely used in food, chemical and pharmaceutical industries. They thermally separate the volatile substance, often water, from the desired product (GEA Wiegand GmbH, 2016). The apparent product diversity leads to a variety of different evaporator designs and operating points to achieve an indulgent as well as economic process. There are several different system designs of falling film evaporators with respect to the number of consecutive passes the product has to go through and the devices used to generate the necessary energy excess(GEA Wiegand $\mathrm{GmbH}, 2016$ ). However, a widely applied design is one with mechanical vapor recompression (Addison et al., 1981), i.e. the volatile substance is compressed mechanically and acts as the heating source for the evaporation process.

Especially in the dairy industry, the concentrate will often be further processed in a spray dryer to produce powder (Early, 1998). In this case, not all of the water in the product can be removed in the evaporator because of the loss of its properties as fluid due to the increasing product viscosity (Quaak et al., 1994). Therefore,

\footnotetext{
* Corresponding author.

E-mail address: schwaer@acin.tuwien.ac.at (C. Schwaer).
}

the last stage in the powder production is always a drying process. However, the energy consumption of the spray dryer is 1020 times higher per $\mathrm{kg}$ of removed water compared to the FFE (Ramirez et al., 2006). Thus, it is reasonable to concentrate the product as much as possible in the FFE before drying and achieving a constant dry matter content of the concentrate is a necessity (van Wijck et al., 1994).

Simulation models of FFEs are developed to get a deeper understanding of the process. Moreover, costs, plant shut-downs and time can be efficiently reduced, as plant staff can be taught by using a simulation model instead of the real plant. Also, novel developments concerning control concepts or system designs can be easily tested in a valid simulation environment, since there is less need for extensive experiments. In particular, instead of widespread PID control approaches (O'Callaghan and Cunningham, 2005), modern control concepts based on the mathematical model such as cascade control (Bakker et al., 2006), model predictive control (MPC) (Quaak et al., 1994; Stefanov and Hoo, 2005), linear quadratic regulation (LQR) (Haasbroek et al., 2013) or flatness-based control (Lvine, 2009) can be established. Among others, the latter facts indicate the significance of developing mathematical models to simulate the FFE process.

In the1960's, first empirically-motivated (Johnson, 1960) and ordinary differential equation (ODE) based (Andersen et al., 1961) FFE 
simulation approaches were started. While other early computer programs to simulate multiple effect evaporators (MEEs) were considered unsuitable and gathered only few attention (Jernqvist et al., 1966), first simple physically-motivated MEE models were implemented on digital computers (Hussey, 1973; Bolmstedt, 1977). In this context, the nonlinear and linear simulation models of Newell and Fisher (Newell and Fisher, 1972) could be experimentally evaluated. Another famous work in this early period was published by Andre and Ritter (Andre and Ritter, 1968), who developed a dynamic FFE model of a two-effect evaporator based on material and energy balances. However, most of these early works only consider strongly simplified behavior of multiple effects since fast dynamics, time delays and other subsystems of FFEs are neglected. Additionally, the obtained equations were linearized around a specific operating point (Newell and Fisher, 1972) and could therefore only describe small deviations in process conditions. Moreover, they use lumped-parameter first-order ODEs to simulate both long- and short-tube evaporators.

In 1990, Tonelli et al. (1990) presented a computer package, where constant time-delays in and between the effects could be included into the simulation model. Further recent studies on dynamic FFE simulation focus on detailed subsystem modeling (Quaak and Gerritsen, 1990; Winchester, 2000; Paramalingam, 2004), usage of dynamic models for control design (Winchester and Marsh, 1999; Bakker et al., 2006; Stefanov and Hoo, 2005) or distributed-parameter effect models (Stefanov and Hoo, 2004; Bojnourd et al., 2015). In all of these full plant simulation models, constant transport velocity and thus constant delay is assumed. However, variations in dry matter content of the feed, changes in the input mass flow to reach new operating points (van Wijck et al., 1994) or use of the input mass flow as manipulated variable to reach control objectives (van Wijck et al., 1994; Stefanov and Hoo, 2005) have an impact on the time delays occurring within the evaporator plant. For this reason, it is necessary to include the impact of these variables on the delays into the simulation model.

Besides dynamic simulation models, there are numerous publications concerning evaporators with different main focuses, e.g. an estimation of the overall heat transfer coefficient (Angeletti and Moresi, 1983), computational aspects (Zain and Kumar, 1996; Koko and Joye, 1987), multiple streams concepts (Westerberg and Hillenbrand, 1988; Khanam and Mohanty, 2011), usage of commercial software (Munir et al., 2014; Zhang et al., 2018), energy saving mechanisms in countercurrent MEEs (Ruan et al., 2015), MEEs in the sugar industry (Srivastava et al., 2013), fouling (DazOvalle et al., 2017), pressure drop along the tubes and interactions between vapor and liquid phase (Gourdon and Mura, 2017), energy reduction schemes (Khanam and Mohanty, 2010) or turbulence in evaporating falling films (Kharangate et al., 2015). In the latter paper, a fully partial differential equation (PDE) based model of evaporating falling film in a tube is implemented in FLUENT. Apart from physical modeling, pure empirically-motivated dynamic FFE models can be obtained by applying neural networks (Russell et al., 2000; Costa and Lima, 2003) or identification-based black box approaches (Quaak et al., 1994). New experimental insights regarding the qualitative behavior of evaporating falling film are given in Gourdon et al. (2015).

The main contribution of this paper is the enhancement of dynamic FFE subsystem models to enable simulation scenarios beyond static operating points. As, to the best of authors' knowledge, only constant delays within and between the effects are considered in the framework of full plant simulations (Tonelli et al., 1990; Quaak and Gerritsen, 1990; Winchester, 2000; Paramalingam, 2004; Bojnourd et al., 2015), a novel dynamic effect (time-variable delays within effects) and pipe model (time-variable delays between effects) to overcome this limitation is presented. Additionally, the derived subsystems are implemented as masked modules in MATLAB®/Simulink. Based on this modular architecture approach, simulations of various FFE designs, e.g. different number of passes or different compressors, can be easily performed.

The rest of the paper is organized as follows. Section 2 introduces the system design of a FFE with four passes. The detailed subsystem model derivations are presented in Section 3. The simulation is executed and compared to measured data of the investigated FFE in Section 4. Section 5 finally concludes this paper.

\section{System design}

Fig. 1 illustrates the general system design considered in this paper. The liquid is applied to the distribution plate which directs it to the effect where it flows downwards inside an arrangement of tubes as a continuous film. The tubes are heated from the outside, i.e. the liquid film starts to boil and evaporates partially, whereby it is concentrated and then reaches a reservoir at the bottom. In order to decrease the energy demand during evaporation and to achieve an optimal product concentration FFEs often have more than one pass. In this case, the obtained concentrate is taken out of the first reservoir and applied to a consecutive distribution plate, i.e. the product is passed through a series of consecutive plates, effects and reservoirs. However, the effects are connected in parallel from the view of the heat chamber since it embeds all present effects of the FFE.

In order to initialize the concentration process, steam referred to as $\dot{m}_{\mathrm{v} \text {,init }}$ is applied to the heat chamber and condenses on the tube's outside, leading to evaporation of the water within the product. The vapor evaporated within the effect is condensed by a compressor and directed into the heat chamber to ensure that the latent heat of vaporization origins primarily from internally generated vapor. This guarantees the energy efficiency of the process.

\section{Model derivation}

In this section all subsystems that form the whole evaporator are modeled. In general, the derived equations are formulated with case differentiations and exclusions of singular points to enable direct and easy implementation. The used symbols and subscripts are depicted in (Table 1 and 2). Additionally, note that the index $j$, which used for indexing the passes, is mostly dropped for visibility purposes.

\subsection{Distribution plate}

The distribution plate consists of a surrounding metal shell and a tank to which the solution is applied, see Fig. 2. Through holes in the bottom of the tank the solution is distributed to the effect's tubes where it forms a thin falling film on the inside. Due to the low pressure inside the FFE and the fact that the solution is superheated when it enters the first distribution plate, the water within the product vaporizes instantaneously, forming the vapor mass flow $\dot{m}_{\text {fsh }}$. Thus, the product cools down to effect temperature $\vartheta_{\mathrm{E}}$ before entering the tank

\subsubsection{Total mass balance}

The model derivation of the distribution plate follows (Paramalingam, 2004). However, the plate thickness is ignored since it has a much smaller influence on the filling height than the orifice edge shape, which has a large impact on the discharge coefficient (Winchester, 2000). Additionally, the derived equations are adapted to be applicable not only to a single stationary operating point. Using Bernoulli's law for the output mass flow, the 


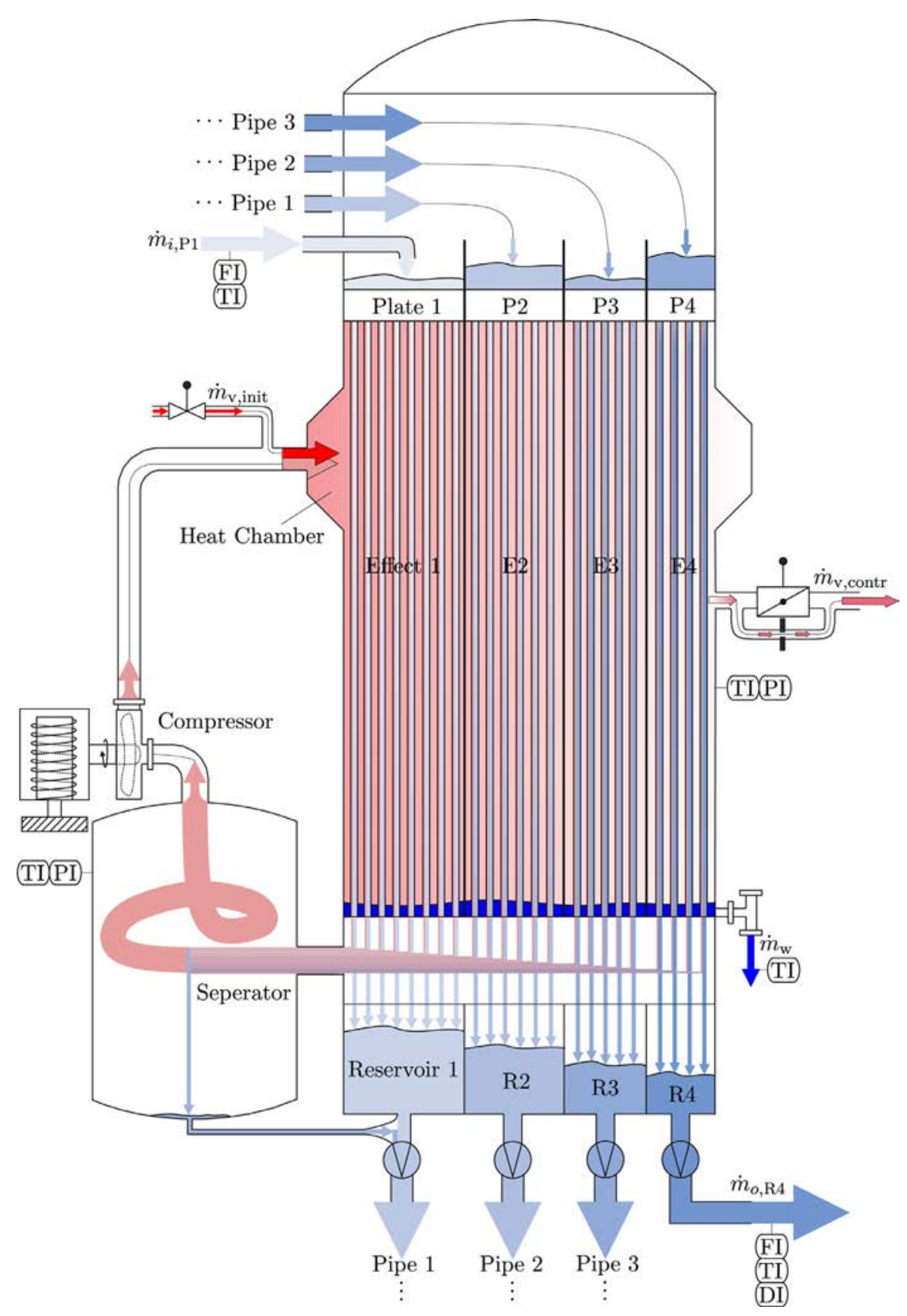

Fig. 1. System design of the falling film evaporator with four passes and mechanical vapor recompression.

equation of the filling height then becomes

$\frac{\mathrm{d}}{\mathrm{d} t} h_{\mathrm{P}}(t)=\frac{\dot{m}_{\mathrm{p}}(t)}{\varrho_{\mathrm{P}}(t) A_{\mathrm{P}}}-\frac{\bar{A}}{A_{\mathrm{P}}} \sqrt{2 g \max \left\{h_{\mathrm{P}}(t), 0\right\}}$,

resembling a first order low pass with

$$
\bar{A}=\frac{n_{0} \zeta_{0} A_{0}}{1-\left[\frac{A_{0}}{A_{\text {virt }}}\right]^{2}} .
$$

It is assumed that the temperature within the distribution plate is approximately the temperature within the effect $\vartheta_{\mathrm{E}}$ and that the vapor as well as the product that reaches the plate adopt this temperature, see also Fig. 2. The mass flow of flashed vapor is deter- mined by

$\dot{m}_{\mathrm{fsh}, \mathrm{P}}(t)=\left\{\begin{array}{l}\frac{\dot{m}_{i, \mathrm{P}}(t) c_{p}(t) \cdot\left[\vartheta_{i, \mathrm{P}}(t)-\vartheta_{\mathrm{E}}(t)\right]}{\left(c_{p, \mathrm{w}}-c_{p}(t)\right) \vartheta_{\mathrm{E}}(t)+\Delta h_{v}\left(\vartheta_{\mathrm{E}}(t)\right)} \\ 0\end{array}\right.$ if $\vartheta_{i, \mathrm{P}}>\vartheta_{\mathrm{E}}$, else

such that the mass flow of product to the plate gets $\dot{m}_{\mathrm{p}}(t)=$ $\dot{m}_{i, \mathrm{P}}(t)-\dot{m}_{\mathrm{fsh}, \mathrm{P}}(t)$.

\subsubsection{Dry mass balance}

As mentioned, the start-up and shut-down processes of the FFE also have to be simulated, i.e. the differential equation of the product's weight fraction has to be adapted since it is a first order differential equation with a singular point at $h_{\mathrm{P}}=0$. The equation 
Table 1

\begin{tabular}{|c|c|}
\hline Symbol & Description \\
\hline$A$ & Area $\left(\mathrm{m}^{2}\right)$ \\
\hline$c_{p}$ & Specific heat capacity $\left(\mathrm{J} \mathrm{kg}^{-1} \mathrm{~K}^{-1}\right)$ \\
\hline$C_{p}$ & Heat capacity $\left(\mathrm{JK}^{-1}\right)$ \\
\hline$d$ & Diameter $(\mathrm{m})$ \\
\hline$D$ & Diffusion coefficient $\left(\mathrm{m}^{2} \mathrm{~s}^{-1}\right)$ \\
\hline$\Delta h_{v}$ & Enthalpy of evaporation $\left(\mathrm{Jkg}^{-1}\right)$ \\
\hline$g$ & Gravitational acceleration $\left(\mathrm{ms}^{-2}\right)$ \\
\hline$h$ & Height $(\mathrm{m})$ \\
\hline$k$ & Heat transfer coefficient $\left(\mathrm{Wm}^{-2} \mathrm{~K}^{-1}\right)$ \\
\hline$L$ & Length $(\mathrm{m})$ \\
\hline$m$ & Mass $(\mathrm{kg})$ \\
\hline$\dot{m}$ & Mass flow rate $\left(\mathrm{kgs}^{-1}\right)$ \\
\hline$n$ & Number $(-)$ \\
\hline$N$ & Number of revolutions $\left(\mathrm{s}^{-1}\right)$ \\
\hline$p$ & Pressure (bar) \\
\hline$P$ & Power $(\mathrm{W})$ \\
\hline$\dot{q}$ & Heat flow rate $(\mathrm{W})$ \\
\hline $\operatorname{Re}$ & Reynolds number (-) \\
\hline$s$ & Falling film thickness (m) \\
\hline$v$ & Specific volume $\left(\mathrm{m}^{3} \mathrm{~kg}^{-1}\right)$ \\
\hline$v_{s}$ & Velocity $\left(\mathrm{ms}^{-1}\right)$ \\
\hline V & Volume $\left(\mathrm{m}^{3}\right)$ \\
\hline$\dot{V}$ & Volume flow $\left(\mathrm{m}^{3} \mathrm{~s}^{-1}\right)$ \\
\hline$w_{d c}$ & Weight fraction dry content $\left(\mathrm{kgkg}^{-1}\right)$ \\
\hline$\gamma$ & Distribution coefficient $(-)$ \\
\hline$\zeta$ & Discharge coefficient (-) \\
\hline$\eta$ & Dynamic viscosity (Pas) \\
\hline$\vartheta$ & Temperature $\left({ }^{\circ} \mathrm{C}\right)$ \\
\hline$v$ & Kinematic viscosity $\left(\mathrm{m}^{2} \mathrm{~s}^{-1}\right)$ \\
\hline$\varrho$ & Density $\left(\mathrm{kgm}^{-3}\right)$ \\
\hline$\tau$ & Time delay (s) \\
\hline
\end{tabular}

Table 2

Subscripts.

\begin{tabular}{ll}
\hline Subscript & Description \\
\hline A & Ambience \\
C & Compressor \\
cond & Condensate \\
contr & Control \\
E & Effect \\
evap & Evaporation \\
fsh & Flash vapor \\
$\mathrm{H}$ & Heat chamber \\
init & Initial \\
inst & Instantaneous \\
$j$ & Effect pass $j$ \\
met & Metal \\
$\mathrm{O}$ & Orifice \\
$\mathrm{p}$ & Product \\
$\mathrm{P}$ & Distribution Plate \\
$\mathrm{R}$ & Reservoir \\
$\mathrm{S}$ & Separator \\
res & Resident \\
$\mathrm{T}$ & Tube \\
$\mathrm{V}$ & Vapor \\
virt & Virtual \\
$\mathrm{w}$ & Water \\
\hline
\end{tabular}

then is

$$
\frac{\mathrm{d}}{\mathrm{d} t} w_{d c o, \mathrm{P}}(t)=\frac{\dot{m}_{\mathrm{p}}(t)}{\varrho_{\mathrm{P}}(t) A_{\mathrm{P}} \max \left\{h_{\mathrm{P}}(t), \epsilon\right\}}\left[w_{d c i, \mathrm{p}}(t)-w_{d c o, \mathrm{P}}(t)\right],
$$

with a small constant $\epsilon>0$ and $w_{d c i, \mathrm{p}}=w_{d c i, \mathrm{P}} \frac{\dot{m}_{i, \mathrm{P}}}{\dot{m}_{\mathrm{p}}}$. For instance, at the start-up process, when the product is applied to the distribution plate the filling level is zero and therefore the output's weight fraction of dry matter instantaneously adapts the weight fraction of the input because of $\frac{\mathrm{d}}{\mathrm{d} t} w_{d c o, \mathrm{P}}(t) \rightarrow \infty$, i.e. the plate acts as a feedthrough with respect to the weight fraction. In this case is $h(t)<\epsilon$, so Eq. (4) becomes a very fast first order low pass since

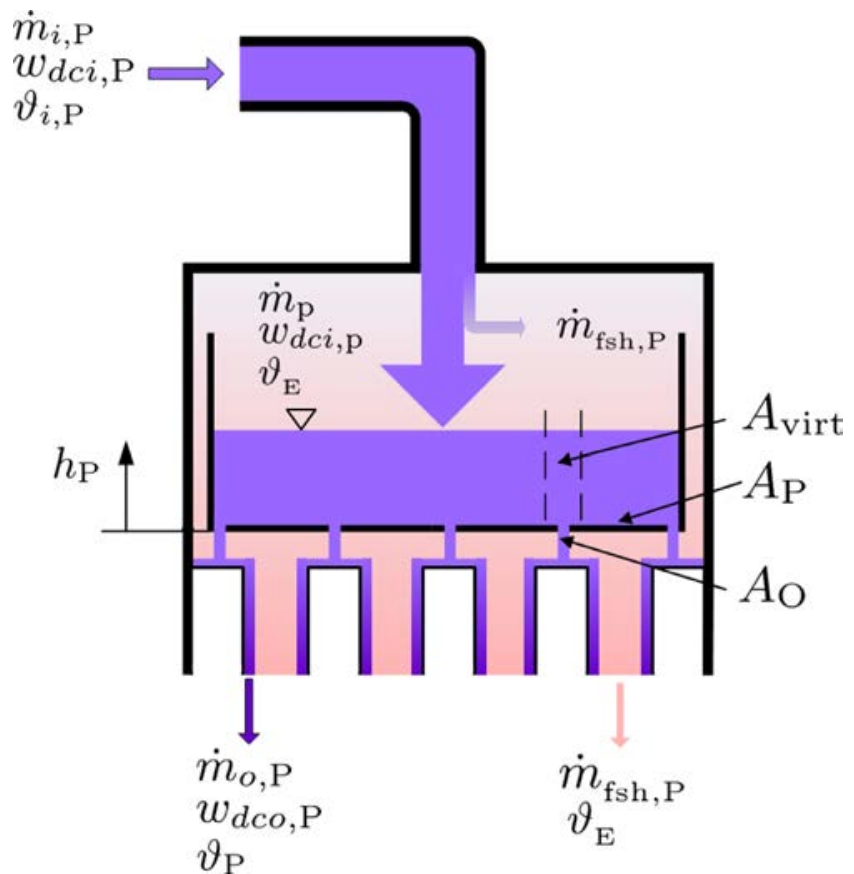

Fig. 2. An incoming product mass flow $\dot{m}_{i, \mathrm{P}}$ is applied and fills the tank within the distribution plate, whereby the filling height is designated as $h_{\mathrm{p}}$. Holes in the bottom distribute the product to the tubes of the following subsystem. The vapor mass flow $\dot{m}_{\text {fsh }}$ occurs due to flashing of the superheated product. $A_{\text {virt }}$ is the plate area $A_{\mathrm{P}}$ divided by the number of orifices.

it can be written as

$\underbrace{\frac{\varrho_{\mathrm{P}}(t) A_{\mathrm{P}} \epsilon}{\dot{m}_{\mathrm{p}}(t)}}_{T} \frac{\mathrm{d}}{\mathrm{d} t} w_{d c o, \mathrm{P}}(t)+w_{d c o, \mathrm{P}}(t)=w_{d c i, \mathrm{p}}(t)$

with a small time constant $T$, i.e. the output weight fraction adapts the input weight fraction quickly and it can be stated that Eq. (4) models the behavior of a feedthrough for the case of a low filling level in good approximation.

\subsubsection{Energy balance}

Assuming negligible change of the product's specific heat capacity, the energy balance of the distribution plate is

$\frac{\mathrm{d}}{\mathrm{dt}}\left[C_{\mathrm{P}}(t) \vartheta_{\mathrm{P}}(t)\right]=\dot{m}_{\mathrm{p}}(t) c_{p, i}(t) \vartheta_{\mathrm{E}}(t)-\dot{m}_{o, \mathrm{P}}(t) c_{p}(t) \vartheta_{\mathrm{P}}(t)$,

where heat transfer to the ambience and between the distribution plates are neglected due to good insulation. The total heat capacity of the plate is given by

$C_{\mathrm{P}}(t)=\varrho_{\mathrm{P}}(t) A_{\mathrm{P}} c_{p}(t) h_{\mathrm{P}}(t)+m_{\text {met }, \mathrm{P}} c_{p, \text { met, } \mathrm{P}}$.

By applying the product rule and $\frac{\mathrm{d}}{\mathrm{d} t} c_{p}=\frac{\mathrm{d}}{\mathrm{d} t} \varrho_{\mathrm{P}}=0$, the left hand side of Eq. (6) yields

$$
\begin{aligned}
\frac{\mathrm{d}}{\mathrm{dt}}\left[C_{\mathrm{P}}(t) \vartheta_{\mathrm{P}}(t)\right]= & \varrho_{\mathrm{P}}(t) A_{\mathrm{P}} c_{p}(t) \vartheta_{\mathrm{P}}(t) \frac{\mathrm{d}}{\mathrm{dt}} h_{\mathrm{P}}(t)+\left(\varrho_{\mathrm{P}}(t) A_{\mathrm{P}} h_{\mathrm{P}}(t) c_{p}(t)\right. \\
& \left.+m_{\text {met, } \mathrm{P}} c_{p, \text { met }, \mathrm{P}}\right) \frac{\mathrm{d}}{\mathrm{dt}} \vartheta_{\mathrm{P}}(t) .
\end{aligned}
$$

Combining Eq. (6) and (8) leads to

$\frac{\mathrm{d}}{\mathrm{dt}} \vartheta_{\mathrm{P}}(t)$

$=\frac{\dot{m}_{\mathrm{p}}(t) c_{p, i}(t) \vartheta_{\mathrm{E}}(t)-\vartheta_{\mathrm{P}}(t)\left[\dot{m}_{o, \mathrm{P}}(t) c_{p}(t)+\varrho_{\mathrm{P}}(t) A_{\mathrm{P}} c_{p}(t) \frac{\mathrm{d}}{\mathrm{dt}} h_{\mathrm{P}}(t)\right]}{\varrho_{\mathrm{P}}(t) A_{\mathrm{P}} c_{p}(t) h_{\mathrm{P}}(t)+m_{\text {met }, \mathrm{P}} c_{p, \text { met } \mathrm{P}}}$. 


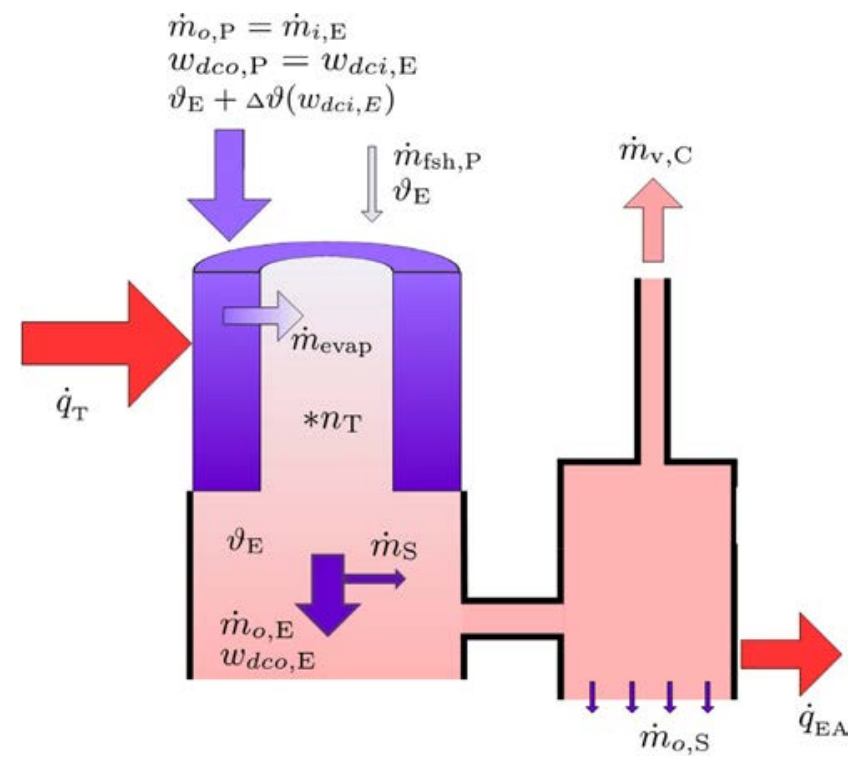

Fig. 3. Schematic of the effect's mass and energy flows. At the top left the product and vapor mass flows enter the effect from the plate. During the product's residence within the tubes, the energy flow $\dot{q}_{\mathrm{T}}$ through the tubes causes an evaporation mass flow $\dot{m}_{\text {evap. }}$. At the bottom the concentrated product leaves the effect. A compressor absorbs the evaporated and flashed vapor $\dot{m}_{\mathrm{v}, \mathrm{c}}$. Due to the high velocity of the vapor, a small part of product $\dot{m}_{S}$ is carried away into the separator, which is neglected in the framework of this paper. Imperfect insulation results in an energy loss to ambience $\dot{q}_{\mathrm{EAA}}$.

\subsection{Effect}

The product, which leaves the distribution plate, is fed to the effect where the solution flows downwards within tubes as a con- tinuous film. Simultaneously, there is a heat flow through the walls of the tubes to evaporate the solvent, i.e. to concentrate the solution. As it flows down the tubes, an increasing amount of solvent is vaporized, such that the concentrated product leaves the tubes at the bottom. A schematic of this process is depicted in Fig. 3.

\subsubsection{Effect model}

In the past, the fundamental models developed for FFEs always used the assumption of constant falling film velocity and uniform evaporation along the tube to transform the partial differential equation into a differential equation with delays (Quaak and Gerritsen, 1990; Winchester, 2000; Paramalingam, 2004). However, the assumption of constant falling film velocity does not hold if the input mass flow is changed which is an important manipulable variable in driving and controlling the evaporator. Also, the assumption of uniform evaporation along the tube is only applicable for fully developed falling films and not during the start-up process. For this reason a discrete model of a conveyor belt is developed as shown in Fig. 4. This model resembles a shift register that moves after every interval $\Delta t$, where $\Delta t$ is the time discretization. Consequently, the mass reaches the tube's end after $\tau_{\mathrm{T}}=r \Delta t$, depending on the register $r$ it was initially filled into. The number of registers is determined by $n=\tau_{\mathrm{T}, \max } / \Delta t$ with $\tau_{\mathrm{T} \text {,max }}$ as a reasonably chosen maximum time delay since $\tau_{\mathrm{T}} \rightarrow \infty$ if $\dot{m}_{i, \mathrm{E}} \rightarrow 0$, see Eq. (11). Using the number of registers $n$ and the tube's length $L$ it follows that the spatial discretization is $\Delta x=L_{\mathrm{T}} / n$. The register $r$ into which the mass is filled is calculated by dividing the instantaneous time delay by the time interval, i.e.

$$
r=\tau_{\mathrm{T}}(t) / \Delta t
$$

with the time delay $\tau_{\mathrm{T}}$ approximated by

$\tau_{\mathrm{T}}(t)=\frac{V(t)}{\dot{V}(t)}=\frac{n_{\mathrm{T}} \pi L_{\mathrm{T}}\left(d_{i, \mathrm{~T}}-s_{\mathrm{T}}(t)\right) s_{\mathrm{T}}(t) \varrho_{i, \mathrm{E}}(t)}{\dot{m}_{i, \mathrm{E}}(t)}$.

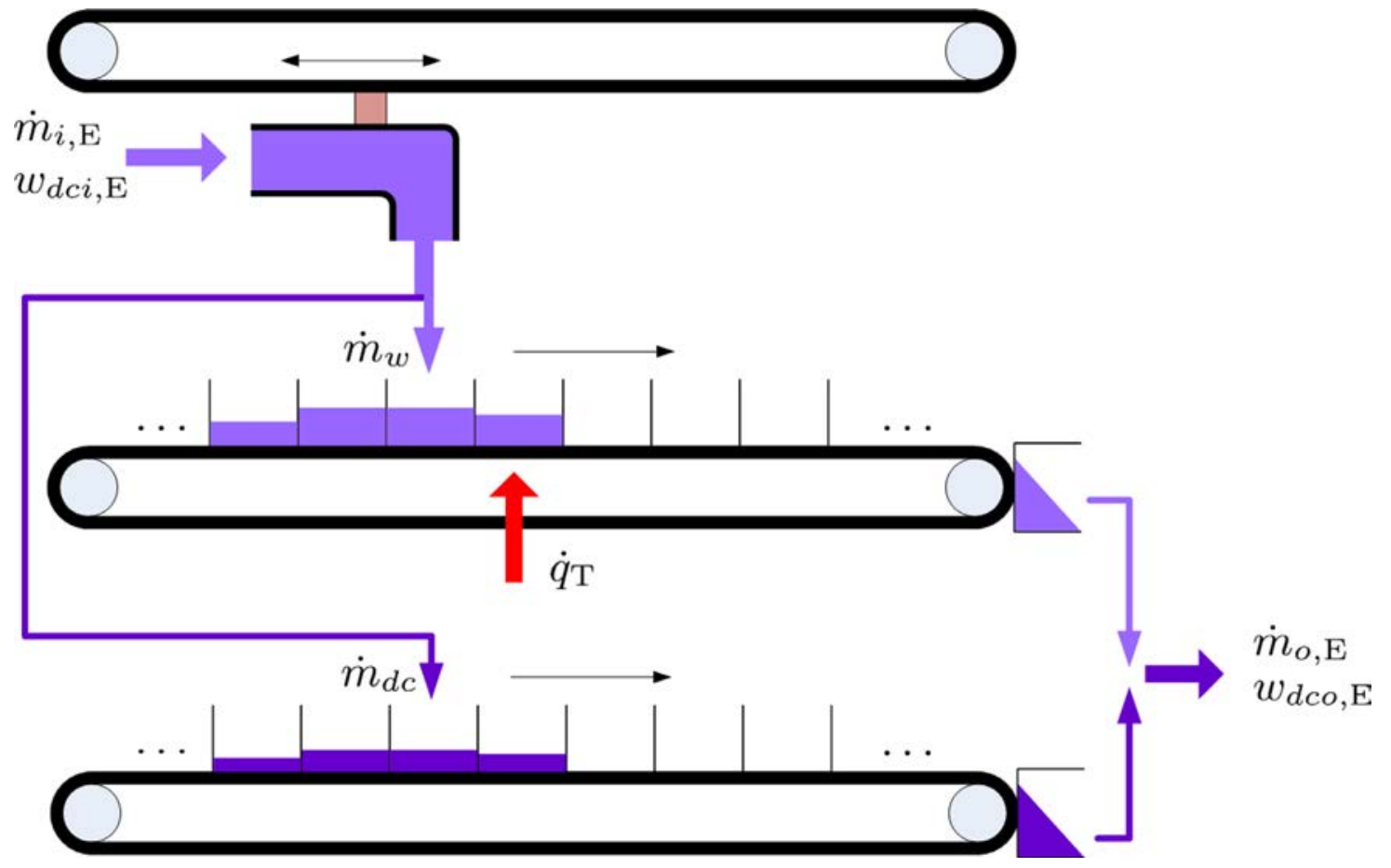

Fig. 4. The dynamic effect model consists of two conveyor belts, one for water and one for dry matter. The number of containers on the belt can be chosen by the program user, as well as the time step after which the containers move one step further. Due to the evaporation process, the water mass within a specific container decreases to the end of the belt where water and dry matter are mixed again, thus creating a concentrated solution. 
It depends on the thickness $s_{\mathrm{T}}\left(\dot{m}_{i, \mathrm{E}}, w_{d c i, \mathrm{E}}\right)$ of the falling film. Based on Nusselt's thin film theory, a formula, see (Verein Deutscher Ingenieure, 2005), to determine $s_{\mathrm{T}}$ is given by

$$
\begin{aligned}
s_{\mathrm{T}} & =\left(\frac{3 v_{\mathrm{p}}^{2}}{g}\right)^{\frac{1}{3}} \operatorname{Re}_{\mathrm{p}}{ }^{\frac{1}{3}}=\left(\frac{3 \eta_{\mathrm{p}}^{2}}{g \varrho_{i, \mathrm{E}}^{2}}\right)^{\frac{1}{3}} \operatorname{Re}_{\mathrm{p}}^{\frac{1}{3}}, \\
\operatorname{Re}_{\mathrm{p}} & =\frac{\dot{m}_{i, \mathrm{E}}}{n_{\mathrm{T}} \pi \eta_{\mathrm{p}} d_{i, \mathrm{~T}}} .
\end{aligned}
$$

The product has to be separated into water and dry matter since the models of the components differ with respect to the evaporation process. Considering that the model is a conveyor belt and that the first state $x_{1}$ represents the last register before the product leaves the tubes, the superdiagonal of the state-space model has to be filled with ones. Additionally, it is assumed that there is a mass balancing amongst adjacent states as well as a water input and vapor output. This leads to

$$
\begin{aligned}
\left(\begin{array}{c}
x_{1} \\
x_{2} \\
\vdots \\
x_{n}
\end{array}\right)_{i+1}= & \left(\begin{array}{cccccc}
\xi & 1-2 \xi & \xi & 0 & \cdots & 0 \\
0 & \xi & 1-2 \xi & \xi & \cdots & 0 \\
\vdots & \vdots & \vdots & \vdots & \ddots & \vdots \\
0 & 0 & 0 & 0 & \cdots & \xi
\end{array}\right)\left(\begin{array}{c}
x_{1} \\
x_{2} \\
\vdots \\
x_{n}
\end{array}\right)_{i} \\
& +\left(\begin{array}{c}
b_{1} \\
b_{2} \\
\vdots \\
b_{n}
\end{array}\right)_{i} m_{\mathrm{w}, i}-\left(\begin{array}{c}
v_{1} \\
v_{2} \\
\vdots \\
v_{n}
\end{array}\right)_{i} m_{\mathrm{v}, i},
\end{aligned}
$$

$y_{\mathrm{w}, i}=\left(\begin{array}{lllll}1 & 0 & 0 & \ldots & 0\end{array}\right) \underline{x}_{i}$,

where $\xi$ denotes the mass balancing and $\underline{x}=\left(x_{1}, x_{2}, \cdots, x_{n}\right)^{T}$. The masses of water and vapor are determined by

$$
\begin{aligned}
& m_{\mathrm{w}, i}=\int_{t_{i}}^{t_{i}+\Delta t}\left(1-w_{d c i, \mathrm{E}}\right) \dot{m}_{i, \mathrm{E}}(\tau) \mathrm{d} \tau \\
& m_{\mathrm{v}, i}=\int_{t_{i}}^{t_{i}+\Delta t} \dot{m}_{\mathrm{evap}}(\tau) \mathrm{d} \tau .
\end{aligned}
$$

The instantaneous evaporation mass flow for determining Eq. (17) within effect pass $j$ is provided by

$\dot{m}_{\mathrm{evap}, j}=\gamma_{\mathrm{j}} \dot{m}_{\mathrm{v}, \mathrm{C}}-\dot{m}_{\mathrm{fsh}, j}$,

where $\dot{m}_{\mathrm{v}, \mathrm{C}}$ is the mass flow through the compressor, see Section 3.3.1, and $\gamma_{j}$ a coefficient to back-calculate $\dot{m}_{\mathrm{v}, \mathrm{C}}$ to each effect pass $j$. This coefficient is obtained by relating the heat flow into pass $j$ to the total energy flow into all passes, i.e.

$\gamma_{j}=\frac{\dot{q}_{\mathrm{T}, j}}{\sum_{j=1}^{n} \dot{q}_{\mathrm{T}, j}}$.

The vector $\underline{b}=\left(b_{1}, b_{2}, \cdots, b_{n}\right)^{T}$ is determined by using the modulo operation $\tau_{\mathrm{T} \text {,mod }}=r \bmod 1$, with the following case differentiation

$$
\begin{aligned}
& \text { if } 0 \leq \tau_{\mathrm{T}, \bmod }<0.5: \quad b_{m}= \begin{cases}1-\tau_{\mathrm{T}, \mathrm{mod}} & \text { if } m=l \\
\tau_{\mathrm{T}, \bmod } & \text { if } m=l+1, \\
0 & \text { else }\end{cases} \\
& \text { if } \quad 0.5 \leq \tau_{\mathrm{T}, \bmod }<1: \quad b_{m}= \begin{cases}\tau_{\mathrm{T} \text { mod }} & \text { if } m=l \\
1-\tau_{\mathrm{T}, \text { mod }} & \text { if } m=l-1, \\
0 & \text { else }\end{cases}
\end{aligned}
$$

where $l=\operatorname{round}(r)$ to the nearest integer. The vector $\underline{v}=$ $\left(v_{1}, v_{2}, \cdots, v_{n}\right)^{T}$ is calculated by

$v_{m}=\left\{\begin{array}{ll}\frac{1}{n_{f s}} & \text { if } x_{m}>0 \\ 0 & \text { else }\end{array}\right.$,

where $n_{f s}$ is the number of filled states. It is ensured, however, that the amount of water within a register can not get zero, i.e. if $v_{m} \cdot m_{v}>x_{m}$, the register $x_{m}$ is emptied and the residual vapor mass is distributed amongst the remaining filled registers. This means that the assumption of uniform evaporation along the tube is given up in the proposed effect model.

The dry matter model is the same as for water, see Eqs. (14)(17), with the difference that the mass $m_{d c, i}$ is calculated by integrating the product $w_{d c i, \mathrm{E}} \dot{m}_{i, \mathrm{E}}$ and $m_{\mathrm{v}, i}=0$. In order to obtain the output mass flow $\dot{m}_{o, \mathrm{E}}$, the masses of water and dry matter in the last register are summed and divided by $\Delta t$. The weight fraction of dry matter $w_{d c o, \mathrm{E}, i}$ is the quotient of $m_{d c, i}$ and $m_{o, \mathrm{E}, i}=m_{d c, i}+m_{\mathrm{w}, i}$.

Consider Eq. (14) as the numerical treatment of the diffusion equation with $\xi=D \Delta t / \Delta x^{2}$. However, in the present case $\Delta x$ and $\Delta t$ to calculate $\xi$ are not chosen independently since they are connected by $\Delta x=L_{\mathrm{T}} / n=L_{\mathrm{T}} \Delta t / \tau_{\mathrm{T} \text {,max }}$. Hence,

$\xi=\frac{D \Delta t}{\Delta X^{2}}=\frac{D \Delta t}{\left(\frac{L \Delta t}{\tau_{T, \max }}\right)^{2}}=\frac{D \tau_{T, \max }^{2}}{L^{2} \Delta t}$.

Note that the Von Neumann stability analysis (Hirsch, 1988), which is used to check the stability of finite difference schemes and is based on the Fourier decomposition of numerical error, demands

$\xi=\frac{D \tau_{T, \max }^{2}}{L^{2} \Delta t}<\frac{1}{2}$,

and consequently

$D<\frac{L^{2} \Delta t}{2 \tau_{T, \max }^{2}}$.

Since it is not a diffusion per se but rather a mass distribution within the tubes, the value of the diffusion coefficient $D$ can not be found in literature. For this purpose, in an existing plant it can be used as an adaptive parameter to tune the model. For testing the feasibility of different, non-existent evaporator designs it can be chosen such that it fulfills Eq. (25) and within this range at the upper limit for a product with small viscosity and closer to zero for one with large viscosity.

\subsubsection{Energy balance}

In literature on FFEs the considered product is mostly milk or dairy products (Cunningham et al., 2006; Paramalingam, 2004; Winchester and Marsh, 1999). In this case it is negligible that the presence of a solute with a specific weight fraction increases the boiling temperature of the solution (Atkins and de Paula, 2006). However, in other products, e.g. glucose, the boiling point elevation has a larger impact, as it drastically influences the effect energy balance. Although the specific heat capacity slightly changes with time due to varying product temperature and dry mass fraction, it is assumed that $\frac{\mathrm{d}}{\mathrm{d} t} c_{p}=0$. On the top and bottom left hand side in Fig. 5, the ingoing and outgoing product flows are displayed, which are both affected by the product's dry matter content and the resulting boiling point elevation. Since the energy flow through the tubes depends on the product temperature, it is approximated along the tubes by the mean of the ingoing and outgoing product temperatures. The energy resulting from vapor flows are shown on the top and bottom right hand side, respectively. The total outgoing vapor energy flow equals the energy flow through the compressor $\dot{q}_{\mathrm{v}, \mathrm{C}}$. On the right hand side the energy loss due to heat conduction to ambience is depicted. As mentioned in Section 2, the effect passes are arranged in parallel which leads to the differential equation for the effect temperature

$$
\frac{\mathrm{d}}{\mathrm{d} t} \vartheta_{\mathrm{E}}=\frac{\sum_{j=1}^{n}\left(\dot{q}_{i, \mathrm{E}}+\dot{q}_{\mathrm{T}}\right)_{j}-\sum_{j=1}^{n}\left(\dot{q}_{o \mathrm{E}}+\dot{q}_{\mathrm{evap}}\right)_{, j}-\dot{q}_{\mathrm{EA}}-\vartheta_{\mathrm{E}} \frac{\mathrm{d} m_{\mathrm{E}}}{\mathrm{dt}} c_{p}\left(\frac{w_{d c}+w_{d c c}}{2}\right)}{m_{\mathrm{E}} c_{p}\left(\frac{w_{d c i}+w_{d c o}}{2}\right)+m_{\text {met }, \mathrm{E}} c_{p, \text { met }}} .
$$




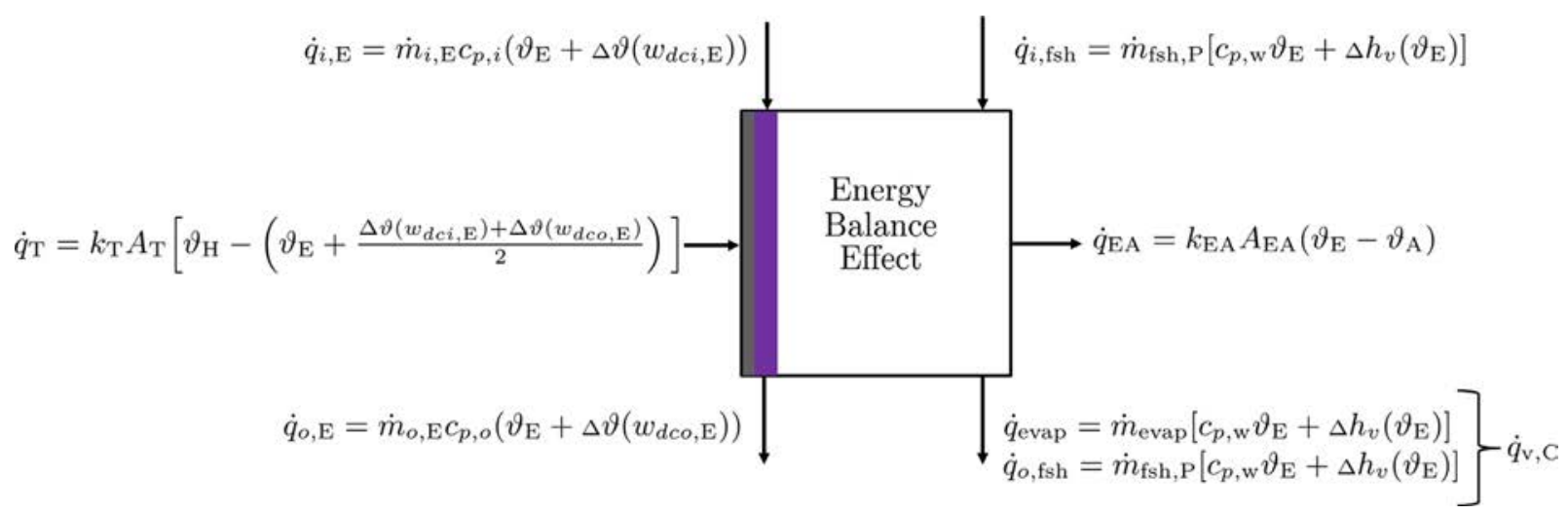

Fig. 5. All energy flows entering and leaving the effect. The product (top left and bottom left), vapor (top right and bottom right), tube (left) as well as loss to ambience (right) are considered to determine the energy balance. In order to achieve a more accurate result, the boiling point elevation $\Delta \vartheta$ due to higher dry mass fraction of the product is added.

The time dependencies are dropped in this equation for better visibility and the expressions of the heat flows can be taken from Fig. 5. Furthermore, the total heat capacity of product in the effect is determined by the sum of product within the tubes of all passes

$m_{\mathrm{E}} c_{p}\left(\frac{w_{d c i}+w_{d c o}}{2}\right)=\sum_{j=1}^{n} m_{\mathrm{T}, j} c_{p}\left(\frac{w_{d c i, E, j}+w_{d c o, E, j}}{2}\right)$,

where $m_{\mathrm{T}, j}$ follows from integrating $\frac{\mathrm{d}}{\mathrm{d} t} m_{\mathrm{T}, j}=\left(\dot{m}_{i, \mathrm{E}}-\dot{m}_{\mathrm{evap}}-\right.$ $\left.\dot{m}_{o, \mathrm{E}}\right)_{, j}$.

\subsection{Heat chamber}

The vaporised water is absorbed by a compressor which increases vapor temperature, thus creating a temperature difference between product and vapor. This gradient is used to induce a heat flow through the wall of the tubes to the solution as shown in Fig. 6. Within the chamber, the vapor condenses at the outside of the tubes, providing its condensation enthalpy to their walls.

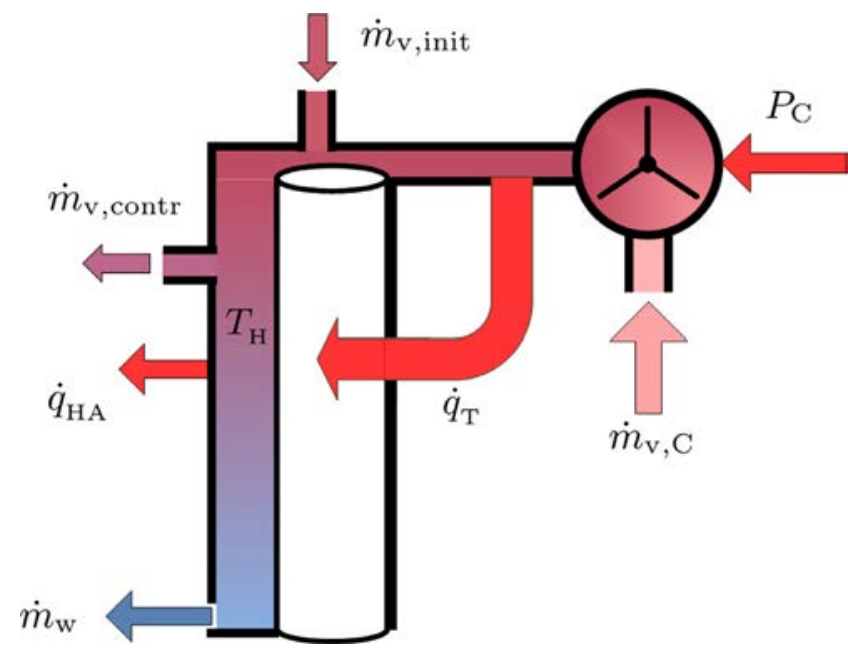

Fig. 6. Mass and energy flows entering and leaving the heat chamber. The compressor sucks in the vapor $\dot{m}_{\mathrm{v}, \mathrm{C}}$ and adds energy due to the supplied power. The vapor condenses on the tubes, providing the energy flow $\dot{q}_{\mathrm{T}}$ through the tube walls into the effect. The condensate is taken out of the chamber at the bottom. For temperature controlling purposes, the excess vapor mass flow $\dot{m}_{\mathrm{v}, \text { contr }}$ leaves the heat chamber through a valve. To start the evaporation process, the live steam mass flow $\dot{m}_{\mathrm{v}, \text { init }}$ is induced. Because of imperfect insulation there is also an energy loss $\dot{q}_{\mathrm{HA}}$ to the ambience.

\subsubsection{Compressor}

The compressor map describes the relationship between compressor speed, vapor suction flow and pressure difference of heat chamber and effect in one diagram as well as vapor suction flow and work done by the compressor in a second one. The algebraic equation for relating volume flow and compressor speed, similar to the derivation in Winchester and Marsh (1999), is

$$
\frac{p_{\mathrm{H}}(t)-p_{\mathrm{E}}(t)}{\varrho_{\mathrm{v}, \mathrm{E}}\left(\vartheta_{\mathrm{E}}(t)\right)}=a N_{\mathrm{C}}(t)^{2}+b N_{\mathrm{C}}(t) \dot{V}_{\mathrm{v}, \mathrm{C}}(t)+c \dot{V}_{\mathrm{v}, \mathrm{C}}(t)^{2},
$$

where $a-c$ are fitting coefficients to fit the equation to the compressor map. By assuming saturated steam conditions, the pressures in heat chamber and effect can be calculated by Antoine Equation (Speight, 2017) using the temperatures determined by related energy balances. Since the compressor speed is known and the unknown variable is the volume flow, Eq. (28) can be expressed as

$\dot{V}_{\mathrm{v}, \mathrm{C}}(t)=\left(\frac{p_{\mathrm{H}}(t)-p_{\mathrm{E}}(t)}{\varrho_{\mathrm{v}, \mathrm{E}}\left(\vartheta_{\mathrm{E}}(t)\right) c}+\left(\frac{b^{2}-4 a c}{4 c^{2}}\right) N_{\mathrm{C}}(t)^{2}\right)^{\frac{1}{2}}-\frac{b}{2 c} N_{\mathrm{C}}(t)$.

The apparent ambiguity of the solution can be eliminated since the energy flow that is inherent to the vapor mass flow has to be roughly equal to $\dot{q}_{\mathrm{T}}$, see Section 3.2.2. However, Eq. (29) only holds around the compressor's operating point. During the start-up process when the compressor speed is still small and the pressure $p_{\mathrm{H}}$ is increasing due to the application of external vapor $\dot{m}_{\mathrm{v}, \text { init }}$, the term under the square root can get negative. Because of that, a case differentiation is applied as follows

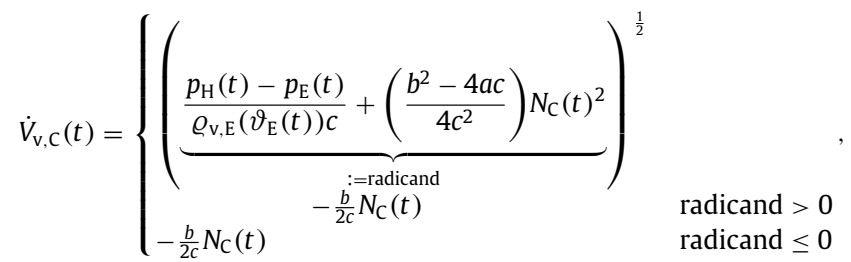

where $a, b>0$ and $c<0$. With the assumption that vapor behaves as an ideal gas, the vapor mass flow is then

$$
\dot{m}_{\mathrm{v}, \mathrm{C}}(t)=\dot{V}_{\mathrm{v}, \mathrm{C}}(t) \varrho_{\mathrm{v}, \mathrm{E}}\left(\vartheta_{\mathrm{E}}(t)\right) \text {. }
$$

The second algebraic equation describes the power supplied by the compressor and is adapted in the following way

$$
\begin{aligned}
P_{\mathrm{C}}(t)= & d \varrho_{\mathrm{v}, \mathrm{E}}\left(\vartheta_{\mathrm{E}}(t)\right) N_{\mathrm{C}}(t)^{3}+e N_{\mathrm{C}}(t)^{2} \dot{m}_{\mathrm{v}, \mathrm{C}}(t) \\
& +f N_{\mathrm{C}}(t) \frac{\dot{m}_{\mathrm{v}, \mathrm{C}}(t)^{2}}{\varrho_{\mathrm{v}, \mathrm{E}}\left(\vartheta_{\mathrm{E}}(t)\right)}+g \frac{\dot{m}_{\mathrm{v}, \mathrm{C}}(t)^{3}}{\varrho_{\mathrm{V}, \mathrm{E}}\left(\vartheta_{\mathrm{E}}(t)\right)^{2}},
\end{aligned}
$$


with the fitting coefficients $d-f$, since the equation given in Winchester and Marsh (1999) disregards the possibility of supplied power even if there is no mass flow which does not coincide with the compressor map.

\subsubsection{Total mass balance}

It is assumed that the incoming vapor distributes throughout the entire volume and condensates evenly along the tubes. Using these assumptions the total mass balance is given by

$$
\frac{\mathrm{d}}{\mathrm{d} t}\left[\varrho A\left(s_{\mathrm{H}}(t)\right) L_{\mathrm{T}}\right]=\dot{m}_{\mathrm{v}, \mathrm{C}}(t)+\dot{m}_{\mathrm{v}, \text { init }}(t)-\dot{m}_{\mathrm{v}, \text { contr }}(t)-\dot{m}_{\mathrm{W}}(t) .
$$

The circular ring area depends on the film thickness $s_{\mathrm{H}}$

$A\left(s_{\mathrm{H}}\right)=n_{\mathrm{T}} \pi\left(d_{o, \mathrm{~T}}+s_{\mathrm{H}}(t)\right) s_{\mathrm{H}}(t)$.

Substituting Eq. (34) into (33) and solving for the derivative of the film thickness yields

$$
\begin{aligned}
\frac{\mathrm{d}}{\mathrm{d} t} s_{\mathrm{H}}(t)= & \frac{1}{n_{\mathrm{T}} \varrho \pi L_{\mathrm{T}}\left(d_{o, \mathrm{~T}}+2 s_{\mathrm{H}}(t)\right)} \\
& \times\left[\dot{m}_{\mathrm{v}, \mathrm{C}}(t)+\dot{m}_{\mathrm{v}, \text { init }}(t)-\dot{m}_{\mathrm{v}, \text { contr }}(t)-\dot{m}_{\mathrm{w}}\left(s_{\mathrm{H}}(t)\right)\right] .
\end{aligned}
$$

For $\dot{m}_{\mathrm{v}, \text { init }}$ and $\dot{m}_{\mathrm{v} \text {,contr }}$ see Section 4.1 and Appendix A. The derivation of outgoing water mass flow follows Padmanaban (2006) with the adaption to falling film on the tube's outer surfaces

$$
\begin{aligned}
\dot{m}_{\mathrm{w}}\left(s_{\mathrm{H}}(t)\right)= & \frac{\pi \varrho g_{z}}{8 v}\left(4\left(r_{o, \mathrm{~T}}+s\right)^{4} \ln \frac{r_{o, \mathrm{~T}}+s}{r_{o, \mathrm{~T}}}\right. \\
& \left.+4 r_{o, \mathrm{~T}}^{2}\left(r_{o, \mathrm{~T}}+s\right)^{2}-r_{o, \mathrm{~T}}^{4}-3\left(r_{o, \mathrm{~T}}+s\right)^{4}\right),
\end{aligned}
$$

where $r_{o, \mathrm{~T}}=\frac{d_{o, \mathrm{~T}}}{2}, \varrho=\varrho_{\mathrm{w}, \text { cond }}, \eta=\eta_{\mathrm{w}, \text { cond }}$ and $s=s_{\mathrm{H}}(t)$. Note that the time dependency of the film thickness disagrees with the assumption of a constant film thickness in the derivation of Eq. (36). However, since $\frac{\mathrm{d} s}{\mathrm{~d} t} \ll 1$, the introduced deviation is very small.

\subsubsection{Energy balance}

Assuming that the vapor's heat capacity is negligible in comparison to the capacity of water and metal as well as $\frac{\mathrm{d}}{\mathrm{d} t} c_{p, \mathrm{w}}=0$, the energy balance of the heat chamber is evaluated. By solving the latter for the temperature, the first-order ODE

$$
\begin{aligned}
& \frac{\mathrm{d}}{\mathrm{d} t} \vartheta_{\mathrm{H}}(t) \\
& \quad=\frac{\dot{q}_{\mathrm{v}, \mathrm{C}}+P_{\mathrm{C}}+\dot{q}_{\mathrm{v}, \text { init }}-\sum_{j=1}^{n} \dot{q}_{\mathrm{T}, j}-\dot{q}_{\mathrm{w}}-\dot{q}_{\mathrm{HA}}-\dot{q}_{\mathrm{v}, \text { contr }}-\vartheta_{\mathrm{H}} \frac{\mathrm{d} m_{\mathrm{w}}}{\mathrm{dt}} c_{p, \mathrm{w}}}{m_{\mathrm{w}} c_{p, \mathrm{w}}+m_{\mathrm{met}, \mathrm{H}} c_{p, \mathrm{met}, \mathrm{H}}},
\end{aligned}
$$

is obtained, where

$$
\begin{aligned}
\dot{q}_{\mathrm{HA}}(t) & =k_{\mathrm{HA}} A_{\mathrm{HA}}\left(\vartheta_{\mathrm{H}}(t)-\vartheta_{\mathrm{A}}(t)\right), \\
\dot{q}_{\mathrm{w}}(t) & =\dot{m}_{\mathrm{w}}(t) c_{p, \mathrm{w}}(t) \vartheta_{\mathrm{H}}(t), \\
\dot{q}_{\mathrm{v}, \text { contr }}(t) & =\dot{m}_{\mathrm{v}, \mathrm{contr}}(t)\left(c_{p, \mathrm{w}}(t) \vartheta_{\mathrm{H}}(t)+\Delta h_{v}\left(\vartheta_{\mathrm{H}}\right)\right), \\
\dot{q}_{\mathrm{v}, \text { init }}(t) & =\dot{m}_{\mathrm{v}, \text { init }}(t)\left(c_{p, \mathrm{w}}(t) \vartheta_{\mathrm{H}}(t)+\Delta h_{v}\left(\vartheta_{\mathrm{H}}\right)\right) .
\end{aligned}
$$

The compressor's power $P_{\mathrm{C}}$ is determined by Eq. (32).

\subsection{Reservoir}

The concentrated solution drops from the tubes to the bottom of the effect and a pump transports the product to the next pass, see Fig. 7. Two different cases can occur depending on the product used and the operating mode of the evaporator, i.e. how much product should be held as reserve: In the first case the filling level never reaches the reservoir and there is only product in the pipe. In the other case there is also product in the reservoir.

Furthermore, with respect to dry matter content two models are considered: the case of perfect mixing, which holds for solu-

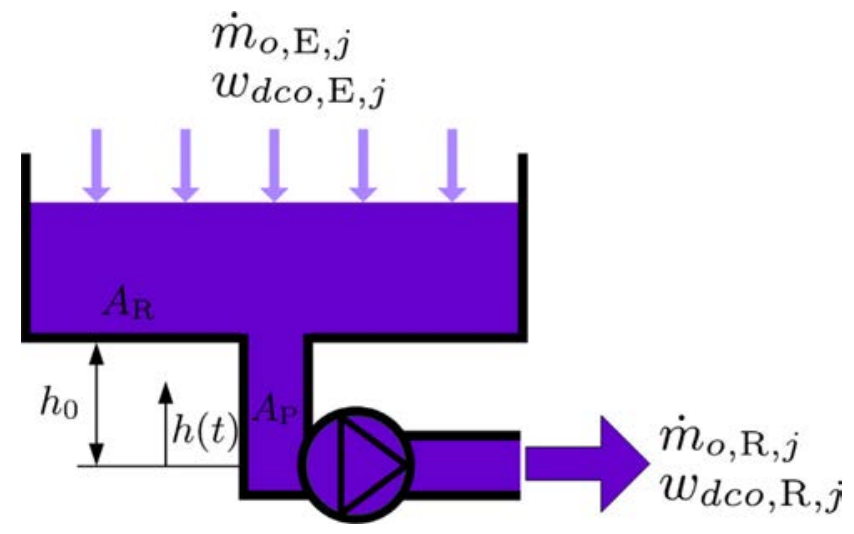

Fig. 7. The product flows out of the effect into a reservoir which usually consist of a vertical pipe with area $A_{\mathrm{P}}$ and a tank with area $A_{\mathrm{R}}$. A pump delivers the product into a pipe which directs it to the subsequent distribution plate.

tions with small viscosity, and layering if viscosity increases due to higher concentration. Both cases can occur simultaneously within one plant, e.g. there is mixing in the first few passes and as the viscosity increases the layering model gives more accurate results in the later passes.

Since there is no significant temperature change along pipe and reservoir due to a good insulation, the product temperature is assumed constant in both of these subsystems.

\subsubsection{Total mass balance}

The total mass balance, considering the different areas of pipe and reservoir is given by

$$
\frac{\mathrm{d} h(t)}{\mathrm{d} t}=\left\{\begin{array}{ll}
\frac{1}{\varrho_{\mathrm{R}}(t) A_{\text {Pipe }}}\left(\dot{m}_{i, \mathrm{R}}(t)-\dot{m}_{o, \mathrm{R}}(t)\right) & \text { if } h(t) \leq h_{0} \\
\frac{1}{\varrho_{\mathrm{R}}(t) A_{\mathrm{R}}}\left(\dot{m}_{i, \mathrm{R}}(t)-\dot{m}_{o, \mathrm{R}}(t)\right) & \text { if } h(t)>h_{0}
\end{array},\right.
$$

where the area of the reservoir can depend on the height, i.e. $A_{R}=$ $A_{\mathrm{R}}(h)$, if the reservoir has a conical instead of a cylindrical shape.

The output mass flow depends on the velocity of the pump. It is turned off if the filling height is smaller than the desired filling height and if the filling height is larger the mass flow is controlled by a PI controller, i.e.

$$
\dot{m}_{o, \mathrm{R}}(t)=\max \left\{k_{p, \mathrm{R}}\left(h(t)-h_{d}\right)+k_{i, \mathrm{R}} \int_{0}^{t}\left(h(\tau)-h_{d}\right) d \tau, \quad 0\right\} .
$$

\subsubsection{Dry mass balance}

In order to obtain the equation describing the dry mass balance in the case of mixing the same approach as in Section 3.1 is used. Again considering the two different cases it is given by

Mixing : $\quad \frac{\mathrm{d}}{\mathrm{d} t} w_{d c o, \mathrm{R}}(t)=\left\{\begin{array}{cc}\frac{\dot{m}_{i, \mathrm{R}}(t)}{h(t) \varrho_{\mathrm{R}}(t) A_{\mathrm{Pipe}}}\left[w_{d c o, \mathrm{E}}(t)-w_{d c o, \mathrm{R}}(t)\right] \\ \frac{\dot{m}_{i, \mathrm{R}}(t)}{\text { if } 0<h(t) \leq h_{0}} \\ \frac{h_{0} \varrho_{\mathrm{R}}(t) A_{\mathrm{R}}}{(h(t)}\left[w_{d c o, \mathrm{E}}(t)-w_{d c o, \mathrm{R}}(t)\right] \\ \text { if } h(t)>h_{0}\end{array}\right.$

In case of layering the model of variable transport delay is applied, see Section 3.5. 


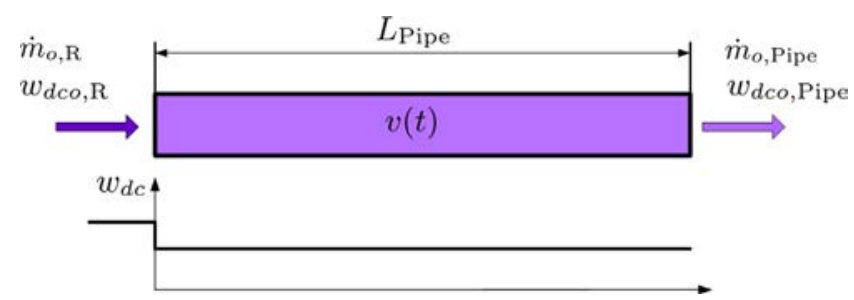

Fig. 8. Formulation of the variable transport delay. A step in product concentration $w_{d c o, R}$ within the mass flow $\dot{m}_{o, \mathrm{R}}$ is applied at the beginning of the pipe. The time until the step reaches the end depends on the variable product velocity $v_{s}(t)$ during residence of the step within the tube.

The instantaneous delay based on the current volume flow can be written as

Layering : $\quad \tau_{\text {inst }, \mathrm{R}}(t)=\frac{V(t)}{\dot{V}(t)}=\left\{\begin{array}{l}\frac{\varrho_{\mathrm{R}}(t) A_{\mathrm{Pipe}} h(t)}{\dot{m}_{o, \mathrm{R}}(t)} \\ \text { if } 0<h(t) \leq h_{0} \\ \frac{\varrho_{\mathrm{R}}(t) A_{\mathrm{R}}\left(h(t)-h_{0}\right)}{\dot{m}_{o, \mathrm{R}}(t)} \text { if } h(t)>h_{0}\end{array}\right.$

\subsection{Pipe}

Besides transport processes within effects, see Section 3.2, there are also transport processes between effects, i.e. from the reservoir of one pass to the distribution plate of the subsequent one. As FFEs with multiple effects are large-scale plants, the summed pipe length can amount to several kilometers. Hence, the transport between effects cannot be neglected. Obviously, transportation of a product always introduces a time delay. In order to model the transportation of a fluid with dry matter, the concept of variable transport delay is introduced. The corresponding Simulink implementation is presented in Zhang and Yeddanapudi. The time it takes for an incompressible fluid mass particle to travel from the input to the output of a pipe depends on the pipe's length and on the velocity of the particle. A formulation of this concept is shown in Fig. 8. The variable transport delay is expressed by the following delay differential equation (DDE):

$\dot{\tau}_{\text {Pipe }}(t)=1-\frac{\tau_{\text {inst,Pipe }}\left(t-\tau_{\text {Pipe }}(t)\right)}{\tau_{\text {inst,Pipe }}(t)}$,

with

$$
\begin{aligned}
\tau_{\text {inst,Pipe }}(t) & =\frac{L_{\text {Pipe }}}{v_{s}(t)}, \\
v_{s}(t) & =\frac{\dot{m}_{o, \mathrm{R}}(t)}{\varrho(t) A_{\text {Pipe }}},
\end{aligned}
$$

and the initial funtion

$\tau_{\text {Pipe }}(\phi)=\frac{L_{\text {Pipe }}}{v_{S}(0)}=\tau_{\text {inst,Pipe }}(0), \quad \phi \in\left[-\tau_{\text {inst,Pipe }}(0), 0\right]$.

\subsubsection{Total mass balance}

In order to simulate start-up processes where $\dot{m}_{o \text { Pipe }}(t)=$ $\dot{m}_{o, \mathrm{R}}(t)$ does not hold since the pipe is empty, the case differentiation

$\dot{m}_{o, \text { Pipe }}(t)= \begin{cases}0 & \text { if } \int_{0}^{t} \frac{\dot{m}_{o, \mathrm{R}}\left(t^{\prime}\right)}{\varrho_{o, \mathrm{R}}\left(t^{\prime}\right)} d t^{\prime}<V_{\text {Pipe }}, \\ \dot{m}_{o, \mathrm{R}}(t) & \text { else }\end{cases}$

is implemented.

\subsubsection{Dry mass balance}

For the derivation of the outgoing dry mass concentration, the concept of variable transport delay is used, such that

$w_{d c o, \text { Pipe }}=w_{d c o, R}\left(t-\tau_{\text {Pipe }}(t)\right)$.

\section{Validation}

In this section, the FFE model presented in Section 3 is validated by comparing simulated data with measured data from a real plant. As not all actuator signals are measured, the validation system is detailed in Section 4.1. Additionally, the plant simulation model is explained in Section 4.2 and corresponding results are discussed in Section 4.4.

\subsection{Validation system}

The considered validation system is depicted in Fig. 9. The plant inputs consist of the measured disturbances $z:=$ $\left[\begin{array}{lll}w_{d c i, \mathrm{P} 1} & \dot{m}_{i, \mathrm{P} 1} & \vartheta_{i, \mathrm{P} 1}\end{array}\right]^{\top}$ and the effective (index $e$ ) actuator signals $u_{1,1}:=\dot{m}_{\mathrm{v}, \text { init,e },}, u_{1,2}:=\dot{m}_{\mathrm{v}, \text { contr }, e}, u_{2}:=N_{\mathrm{C}, e}$. The known signal $\tilde{u}_{2}:=N_{C, d}$ describes the desired (index $d$ ) compressor speed, which is determined by a model predictive controller (MPC) controlling the product density $y_{2}:=\varrho_{0, \mathrm{R}}$ in the fourth reservoir. In this context, the $\mathrm{PT}_{1}$ dynamic

$T_{\mathrm{C}} \frac{\mathrm{d} u_{2}(t)}{\mathrm{d} t}+u_{2}(t)=\tilde{u}_{2}(t), \quad u_{2}(0)=0$

represents the compressor actuator. The MISO model for the MPC considers the final product density as controlled variable, the compressor speed as manipulated variable and variables such as input mass flow and weight fraction as disturbances. The transfer functions, which describe the behavior amongst the output and the inputs, are first and second order low pass filters, integrators and time delay elements. Hence, the transfer matrix consists of simple linear dynamic elements. In order to identify the parameters, step response experiments were executed. Compared to the application of a PI controller to control output dry mass contents, where startup and shut-down processes have to be controlled manually, the MPC controller allows for an automation of larger parts of these processes.

Since $u_{1,1}$ and $u_{1,2}$ cannot be measured, the closed loop to control the effect temperature $y_{1}:=\vartheta_{\mathrm{E}}$ must be included into the validation system. The desired effect temperature $y_{1, d}$ is a constant and depends on the considered product, hygienic and safety constraints as well as on the succeeding process. The control deviation enters a PI controller with $k_{p}=1.8, k_{i}=0.004 \mathrm{~s}^{-1}$ and anti reset windup, cf. (Kothare et al., 1994), as well as a saturation with lower limit 0 and upper limit 1 to generate the signal $\tilde{u}_{1} \in[0,1]$. The latter is split into the live steam valve position $\tilde{u}_{1,1} \in[0,1]$ and the excess vapor valve position $\tilde{u}_{1,2} \in[0,1]$ using the following splitter characteristic

$\tilde{u}_{1,2}=-\frac{20}{11} \tilde{u}_{1}+1, \quad \tilde{u}_{1} \in[0,0.55]$,

$\tilde{u}_{1,1}=\frac{20}{11} \tilde{u}_{1}-\frac{9}{11}, \quad \tilde{u}_{1} \in[0.45,1]$.

The valve positions enter the dynamics $\psi_{1}$ and $\psi_{2}$, which represent the valve characteristics and actuator dynamics of the live steam valve and the excess vapor valve, respectively. See Appendix A for further information. Thus, the corresponding effective mass flows are obtained. The plant simulation model itself is detailed in the following section.

\subsection{Plant simulation model}

In order to implement the simulation model, the Simulink environment of MATLAB is used. A major advantage of using Simulink 


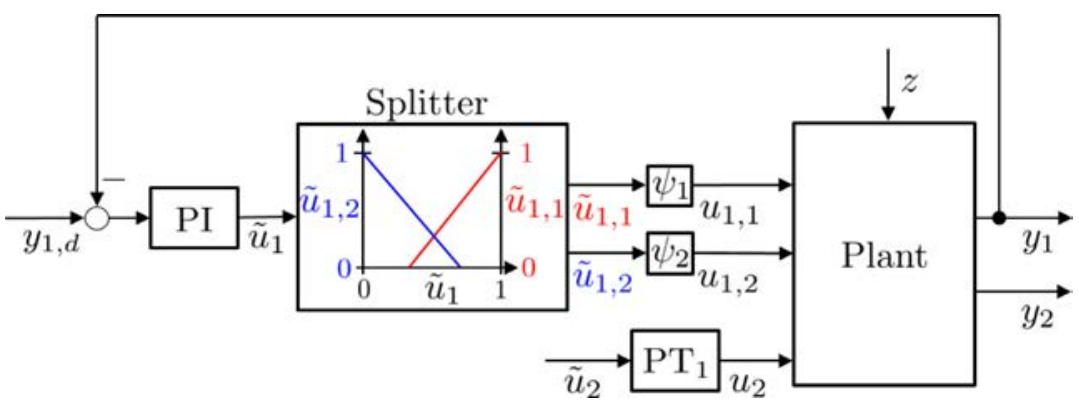

Fig. 9. The validation system consists of the closed loop to control the effect temperature $y_{1}$ by applying PI control with split-range operation. The obtained valve positions $\tilde{u}_{1,1}$ and $\tilde{u}_{12}$ are converted into the live steam mass flow $u_{11}$ and the excess vapor mass flow $u_{12}$, respectively, via the dynamics $\psi_{1}$ and $\psi_{2}$. Also, there are further measured plant inputs, where $z$ represents the input product dry mass fraction, mass flow and temperature. Additionally, the desired compressor speed $\tilde{u}_{2}$ is the known output of a MPC, where the $\mathrm{PT}_{1}$ element describes the compressor's actuator dynamic generating the effective compressor speed $u_{2}$ to control the product density $y_{2}$ in the fourth reservoir.

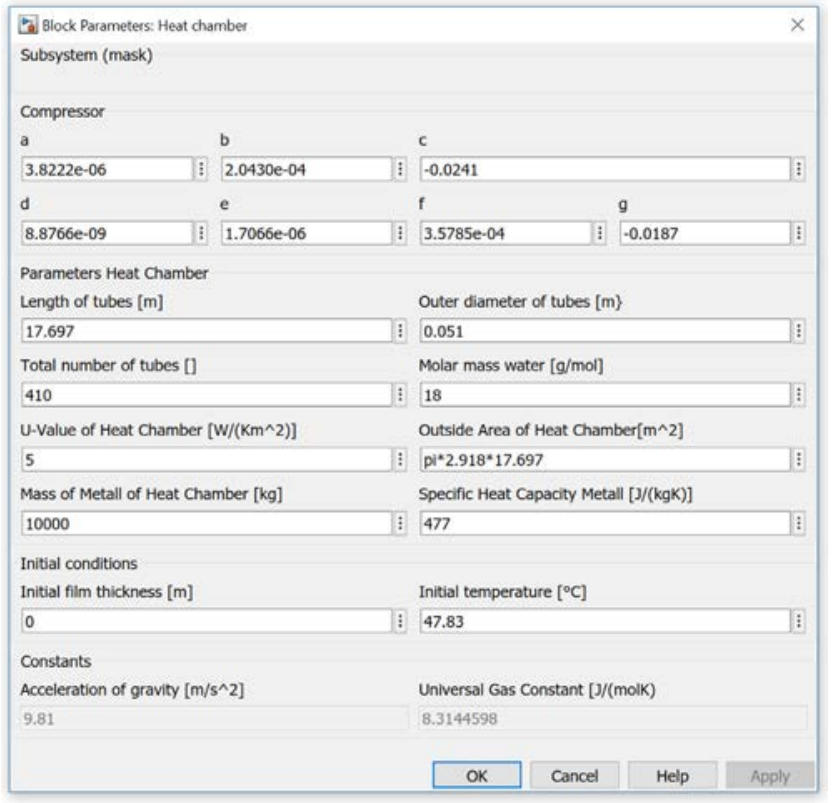

Fig. 10. Simulink mask of a Heat Chamber module.

is the possibility to transfer the modular design of the mathematical model into the simulation model. Corresponding parameters can be set via masks. Hence, masked modules for Plate with Effect, Energy Balance Effect, Heat Chamber, Reservoir and Pipe are developed. Fig. 10 illustrates the mask of a Heat Chamber module to give an example. Based on these elements, FFEs with arbitrary design, e.g. number of passes, can be simulated in a simple manner.

Firstly, note that the plate and effect model is combined under one mask, since all plate outputs only affect the subsequent effect and the number of plates corresponds to the number of effects. Additionally, the effect energy balance is implemented as extra module, since it gets inputs from each single effect. Secondly, the dynamic effect model, see Section 3.2.1, is used for validation purposes to get an online estimation of the time delay within effects.

In the application on hand, a FFE with four passes is considered. Thus, the simulation experiment's plant, which is referred to in Section 4.1, consists of four Plate with Effect (Eq. (1)-(9) and Eq. (11)-(25)) modules, which are each connected by Pipe (Eq. (43)-(48)) and Reservoir (Eq. (39)-(42)) modules, as well as one Heat Chamber (Eq. (28)-(38d)) and one Energy Balance Effect module (Eq. (26)-(27)). The plant simulation model is shown in Fig. 11.

\subsection{Numerical details}

The simulations are performed using MATLAB R2018b on an Intel ${ }^{\circledR}$ Core i7 $2.80 \mathrm{GHz}$ system with $16 \mathrm{~GB}$ RAM and 64 bit Windows ${ }^{\circledR} 10$ as operating system. Since the FFE consists of four passes with the subsystems presented in Section 3, the whole model is a large system of differential-algebraic equations (DAE), plus the developed discrete effect model. Due to the multiple time scale dynamics of the system, e.g. rather slow temperature change and very fast mixing during the start-up process, the set of ordinary differential equations is considered to be stiff. For this reason, MATLAB's ode15s solver for stiff differential equations and DAEs is used with variable step size. The numerically important parameters of the effect model are chosen to $\Delta t=1 \mathrm{~s}, \tau_{T, \max }=120 \mathrm{~s}$ and $D=0.01 \mathrm{~m}^{2} / \mathrm{s}$ for the product at hand.

In order to apply the simulation model in online model based operation technology such as real-time optimization and control, the computational effort has to be suitably low. Although the proposed fundamental model results in stiff DAEs, the time required for simulating the start-up process, which lasts 138 minutes, is about 5 to 6 minutes. This time includes model initialization, solving and plotting of the results. Due to the fast simulation time, the utilization of this model in online applications is apparent.

\subsection{Results and discussion}

In this section, the validation of the simulation model is performed by comparing simulated plant outputs against measured ones. As the disturbances $z$ are known by measurements, the simulation model is fed by these measured inputs. While the control $\tilde{u}_{2}$ is known as it is the output of an MPC, the mass flows controlling the effect temperature are not recorded due to safety, effort and cost constraints. Hence, they are determined by including the effect temperature control loop, see Fig. 9, into the simulation model.

Due to the general model assumption that saturated vapor is the only gaseous medium in the FFE, the start-up process within the simulation is simplified as follows:

1. $t \in[0,200] \mathrm{s}$ : Water is induced onto plate 1 and flows through all passes for cleaning purposes (blue).

2. $t \in(200,460] \mathrm{s}$ : The live steam valve is fully opened, such that $\dot{m}_{\mathrm{v} \text {,init }}$ is induced at the pressure side of the compressor to heat up the effect tubes. Moreover, the compressor is started up (red).

3. $t \in(460,8260] \mathrm{s}$ : The effect temperature control loop is active. Furthermore, product enters the evaporator instead of water at $t=2000 \mathrm{~s}$, which can be concluded from Fig. 12b (green). 


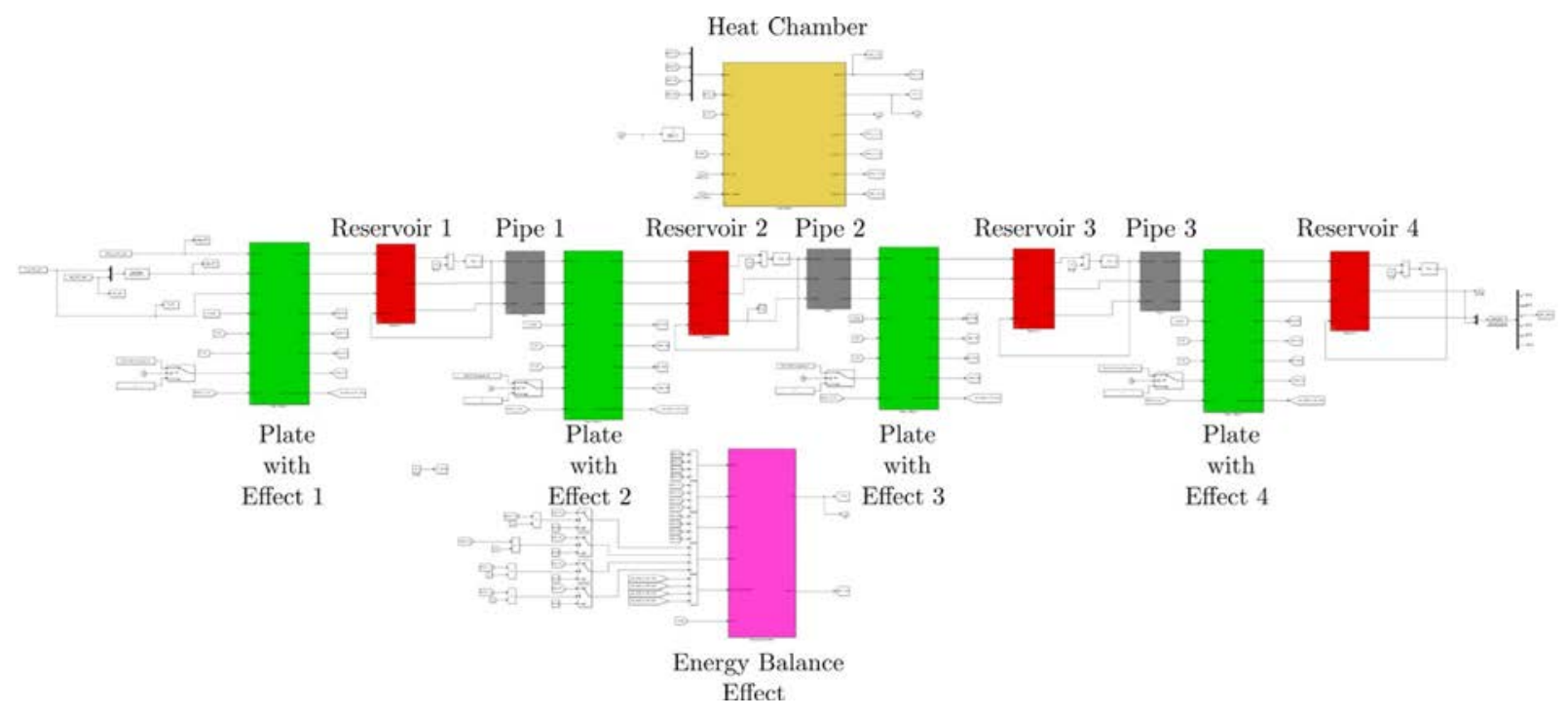

Fig. 11. Plant Simulation Model.

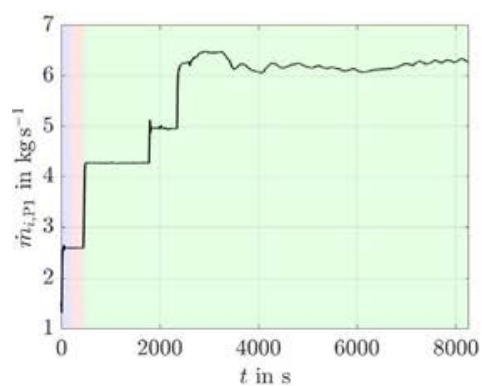

(a) Mass flow onto plate 1

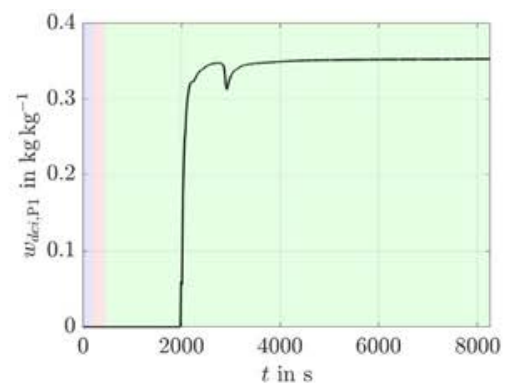

(b) Dry mass fraction onto plate 1

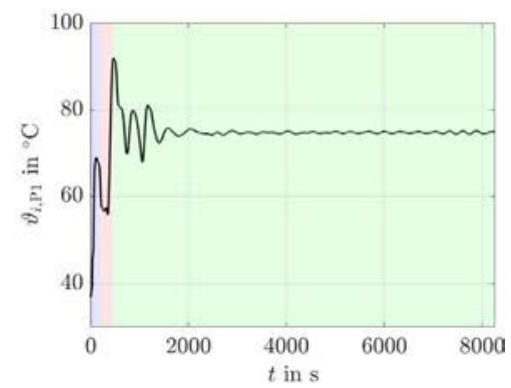

(c) Temperature onto plate 1

Fig. 12. Measured product input quantities (disturbances) for the simulated validation system.

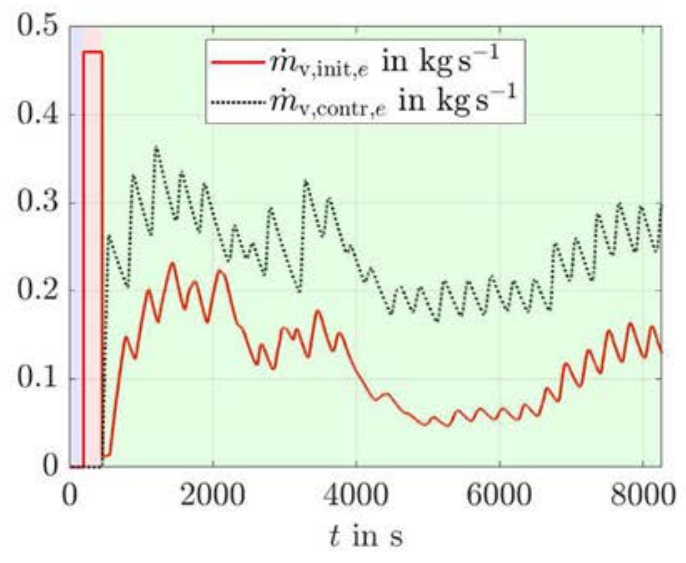

(a) Effective mass flows generated by closed effect temperature loop model

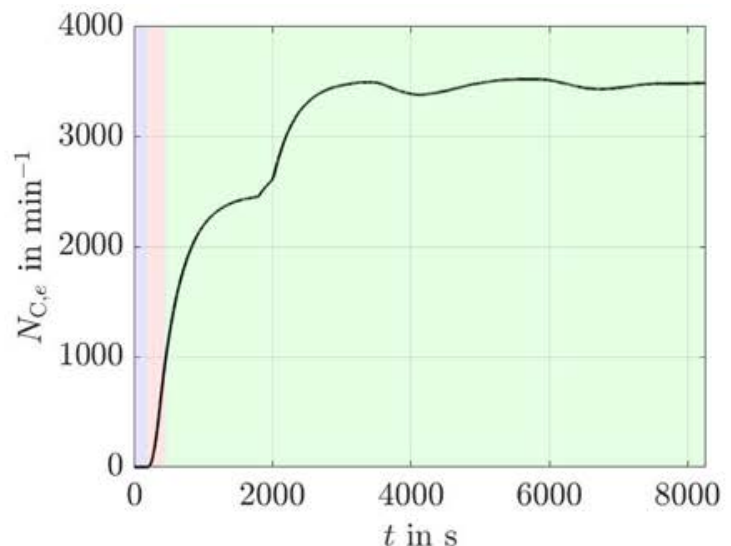

(b) Effective compressor speed generated by real $\mathrm{MPC}$ and $\mathrm{PT}_{1}$ actuator dynamic

Fig. 13. Controls of the simulated validation system.

Note, that the colors inside the brackets of 1 . to 3 . refer to the background colors in Figs. 12-14, in order to illustrate the current process step. Also, in the real process there is only pure air as gaseous medium in the FFE at the beginning. After the air is vacuumed and the desired pressure is set, the product is induced and vapor expands until air and vapor phase are in thermodynamic equilibrium. However, since this process step cannot be simulated by the model, it has to be neglected in the framework of this paper.

The simulated and measured effect temperature as well as heat chamber temperature are depicted in Fig. 14. The final product density is illustrated in Fig. 15. For the effect temperature shown in Fig. 14a, the dynamic behavior and steady-state value of simulated and measured signal are in very good agreement. 


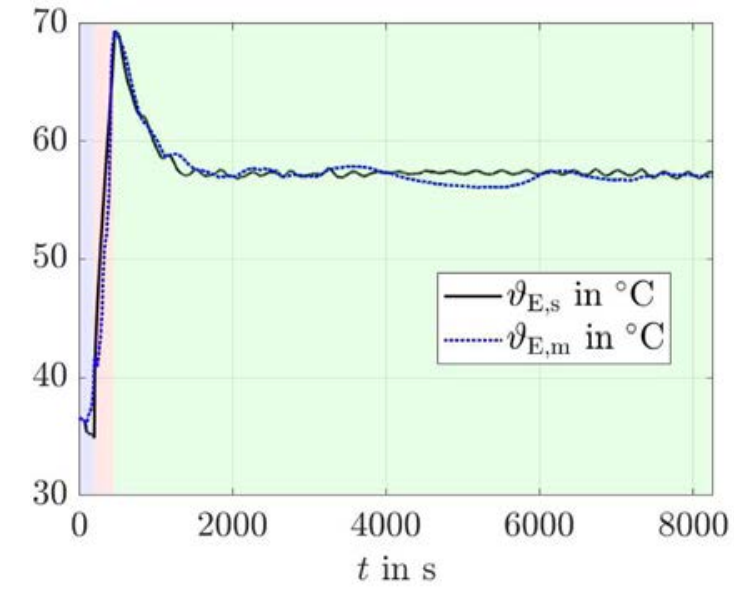

(a) Effect temperature

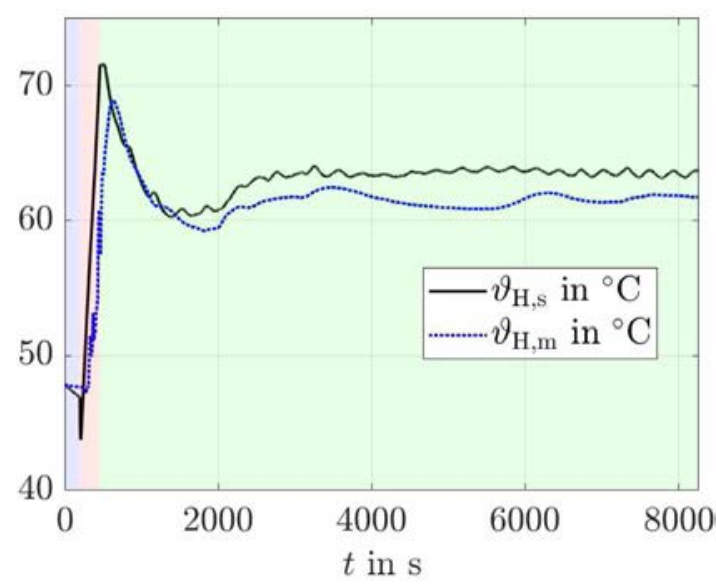

(b) Heat chamber temperature

Fig. 14. Comparison of measured (index m) against simulated (index s) validation system outputs.

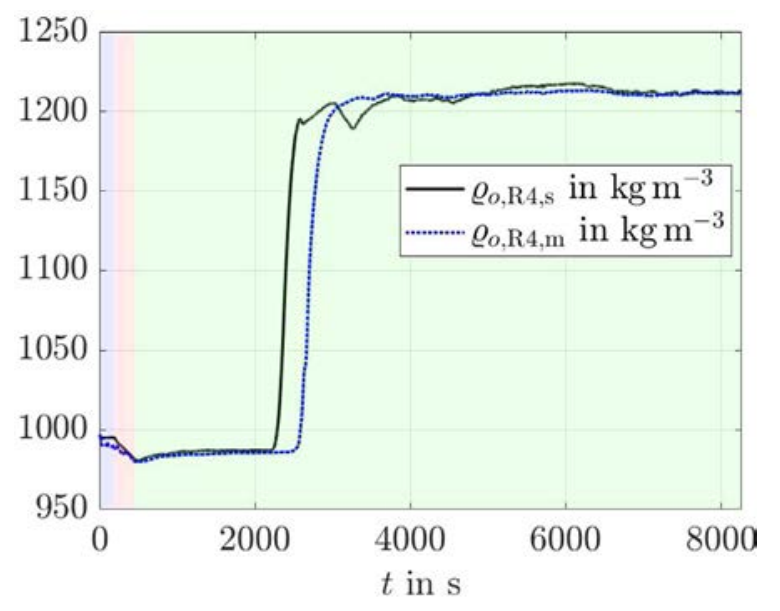

Fig. 15. Product density in reservoir 4.

The measured heat chamber temperature is approximately $1.5^{\circ} \mathrm{C}$ lower than the simulated one, see Fig. 14b. This deviation can be explained by model and measurement uncertainty. Among others, the model uncertainty results from imperfect estimations of constant heat transfer coefficients, which are actually time-varying due to varying amount of vapor on metal parts such as tubes, effect or heat chamber shells. The measurement uncertainty depends on both, the positioning of temperature sensors and the inherent measurement uncertainty of approximately $0.5^{\circ} \mathrm{C}$, since the considered medium is vapor where the measurement of temperature is comparatively inexact. The observed oscillations in both simulated temperatures originate from the oscillations in the controlled mass flows as shown in Fig. 13(a) and cannot be detected in the measured ones due to the inertia of the corresponding measuring devices.

The final product density shown in Fig. 15 also maps the dynamic and stationary behavior of the real plant well. However, there is a remarkable deviation between measured and simulated data in the time delay along the whole plant of approximately $29 \%$. In the model, time delays occur due to effect (see Section 3.2.1) and pipe (see Section 3.5) elements. Thus, the observed deviations can origin from neglected time delays in other plant elements, e.g. if the assumption of perfect mixing within the distribution plate or reservoir does not hold for this product. The product masses in these subsystems as well as the output mass flows during steady-state operation of the evaporator are depicted in Table 3. As can be seen for the distribution plates, there is a factor of 15 to 20 between masses and mass flows which means there might be additional time delay of equal value in case of no mixing. Due to the filling height of only around $50 \mathrm{~mm}$ however, it is reasonable to assume a rather quick mixing of product within the plate and product input flow. The filling height of product within the reservoir is controlled to $1.5 \mathrm{~m}$, therefore imperfect mixing might have an influence on the observed time delay. Since product mass and flow are in the same range in this evaporator, an additional time delay of a couple of seconds at most would be introduced.

Furthermore, the discrepancy could originate from neglected subsystems. For example, the falling time of product from the effect to the reservoir is not considered. Assuming a free fall of product, i.e. neglecting acceleration by the fast flowing vapor around, with an initial velocity of the falling film the introduced time delay is in the range of a few seconds over the whole plant, thus explaining only $1 \%$ of the total deviation. This

Table 3

Masses of product within the subsystems and output mass flow.

\begin{tabular}{llll}
\hline Subsystem & Filling height $(\mathrm{m})$ & Product mass $(\mathrm{kg})$ & Output mass flow $(\mathrm{kg} / \mathrm{s})$ \\
\hline Distr. Plate 1 & 0.0523 & 127.55 & 6.2 \\
Distr. Plate 2 & 0.0542 & 111.93 & 5.6 \\
Distr. Plate 3 & 0.0519 & 91.89 & 5.1 \\
Distr. Plate 4 & 0.0448 & 63.35 & 4.7 \\
Reservoir 1 & 1.5 & 7.1 & 5.6 \\
Reservoir 2 & 1.5 & 4.65 & 5.1 \\
Reservoir 3 & 1.5 & 4.7 & 4.7 \\
Reservoir 4 & 1.5 & 4.8 & 4.4 \\
\hline
\end{tabular}


Table 4

Calculated time delays within Effects.

\begin{tabular}{ll}
\hline Subsystem & Time delay (s) \\
\hline Effect 1 & 46.5 \\
Effect 2 & 52.5 \\
Effect 3 & 63.5 \\
Effect 4 & 74 \\
\hline
\end{tabular}

leaves model uncertainties in effect and/or pipe delays as main contributors.

The time delay within the effect is calculated by the incoming mass flow and weight fraction, see Eq. (11). During the residence in the effect, the weight fraction and the viscosity increases, therefore slowing down the falling film. Table 4 shows the calculated time delays for every effect pass in steady-state operation. Considering that the product at the end of one effect has the same delay as at the top of the subsequent one, up to $10 \%$ of the deviation is explained by simply taking the arithmetic mean of two subsequent time delays for the average time delay in the first effect. In a dynamic process the weight fraction effect output is unknown at the time the delay is calculated, which is why the implementation of e.g. an estimator should improve the model.

Even with this improvement, there is still a significant discrepancy between measured and simulated data, however. This might be due to the fact that Eqs. (11)-(13) which assume a laminar and smooth falling film do not correctly determine the time delay of product in the effect in the present case. A further assumption that might lead to differences in time delay is the one of an incompressible fluid within the pipe, which strictly only holds for water. An increasing dry matter content raises the compressibility and should therefore increase the time delay, too.

Of course, by applying the static effect model as shown in (Quaak and Gerritsen, 1990; Winchester, 2000; Paramalingam, 2004), instead of the dynamic one, the constant time delays within the effects could have been adapted offline to perfectly fit the measured data. However, in an online environment, i.e. the simulation model is fed by the current real plant inputs, an offline adaption of constant effect delays would be impossible. Hence, it is emphasized that the developed model can be used as digital twin of a real FFE, since it is able to dynamically react to time-varying inputs in real-time. It is also suitable for testing of non-existent evaporators since a very high precision of the inherent time delays is not the most crucial parameter in a feasibility study. Nevertheless, the observed deviation motivates further research regarding model precision and model-based control of FFEs.

In summary, the proposed model is suitable to be easily adapted to various evaporator designs as well as plant parameters and simulates dynamic effects within the evaporator very well.

\section{Conclusion}

In this study, a modular, physically-motivated simulation model for FFEs to handle time-varying transport delays is derived. A comparison with real plant data has shown that the dynamics and parameter values are accurately simulated.

Observed deviations with respect to the time delay along the whole plant offer and motivate future research. In this study, the variable time delay along effect tubes depends on the film thickness based on Nusselt's theory. Also, product incompressibility is assumed for the time-varying transport in pipe elements. In this context, it is questionable if these assumptions still hold for every product as well as increasing product concentrations. Since knowing the product properties is always the first step in designing an evaporator, it is planned to extend the test protocol by a sin- gle tube experimental setup for time delay estimations and a pipe element for compressibility tests. Besides that, further studies on transport modeling of fluids will follow to improve model precision in order to not only create a digital twin of an existing FFE and configure new FFE designs or features in advance, but also to enable model based controller synthesis.

\section{Declaration of Competing Interest}

The authors have no affiliation with any organization with a direct or indirect financial interest in the subject matter discussed in the manuscript.

\section{Acknowledgments}

This work has been supported in part by Institute for Automation and Applied Informatics, Karlsruhe Institute of Technology, as well as GEA Wiegand $\mathrm{GmbH}$.

\section{Appendix A. Valves}

To simulate the closed effect temperature loop, two valves are modelled: a valve to induce the live steam mass flow $\dot{m}_{\mathrm{v}, \text { init }}$ (index 1, live steam valve) and a valve to release the excess vapor mass flow $\dot{m}_{v, \text { contr }}$ (index 2 , excess vapor valve). The model of these valves (Auinger et al., 2018) essentially converts the splitter outputs $\tilde{u}_{1,1}, \tilde{u}_{1,2} \in[0,1]$ representing desired valve positions into desired mass flows via

$$
\begin{gathered}
\dot{m}_{\mathrm{v}, \text { init }, d}=\left\{\begin{array}{cc}
31.62 K_{V, 1}\left(\tilde{u}_{1,1}\right)\left(\frac{v_{2,1}}{p_{1,1}-p_{1,2}}\right)^{-\frac{1}{2}}, & p_{1,2}>\frac{p_{1,1}}{2} \\
31.62 K_{V, 1}\left(\tilde{u}_{1,1}\right)\left(\frac{2 v_{1}^{*}}{p_{1,1}}\right)^{-\frac{1}{2}}, & p_{1,2} \leq \frac{p_{1,1}}{2}
\end{array},\right. \\
\dot{m}_{\mathrm{v}, \text { contr }, d}=\left\{\begin{array}{cc}
31.62 K_{V, 2}\left(\tilde{u}_{1,2}\right)\left(\frac{v_{2,2}}{p_{2,1}-p_{2,2}}\right)^{-\frac{1}{2}}, & p_{2,2}>\frac{p_{2,1}}{2} \\
31.62 K_{V, 2}\left(\tilde{u}_{1,2}\right)\left(\frac{2 v_{2}^{*}}{p_{2,1}}\right)^{-\frac{1}{2}}, & p_{2,2} \leq \frac{p_{2,1}}{2}
\end{array},\right.
\end{gathered}
$$

where $K_{V, 1}\left(\tilde{u}_{1,1}\right)$ and $K_{V, 2}\left(\tilde{u}_{1,2}\right)$ are the corresponding valve characteristics. The specific volumes $v_{2, i}=v\left(p_{i, 2}, \vartheta_{i, 1}\right)$ and $v_{i}^{*}=$ $v\left(\frac{p_{i, 1}}{2}, \vartheta_{i, 1}\right)$ with $i=1,2$ are determined by Matlab's Xsteam.m. In order to simulate the valve actuators, both $\dot{m}_{\mathrm{v}, \text { init, } d}$ and $\dot{m}_{\mathrm{v}, \text { contr, } d}$ each pass a $\mathrm{PT}_{1}$ element to obtain the corresponding effective mass flows $u_{1,1}$ and $u_{1,2}$, i.e.

$\begin{array}{lll}T_{\mathrm{V} 1} \frac{\mathrm{d} u_{1,1}(t)}{\mathrm{d} t}+u_{1,1}(t) & =\dot{m}_{\mathrm{v}, \text { init, }, d}(t), & u_{1,1}(0)=0, \\ T_{\mathrm{V} 2} \frac{\mathrm{d} u_{1,2}(t)}{\mathrm{d} t}+u_{1,2}(t) & =\dot{m}_{\mathrm{v}, \text { contr }, d}(t), & u_{1,2}(0)=0 .\end{array}$

The dynamics $\psi_{1}$ and $\psi_{2}$ described in Section 4.1 combine Eq. (A.1) with Eq. (A.2).

\section{Appendix B. Product Properties}

The product to be concentrated has a large influence on the design of a FFE, e.g. the number of passes. Moreover, the effect and heat chamber temperatures have to be carefully adapted to the considered product. On the one hand, these temperatures should be high enough to evaporate the product, while on the other, too high temperatures might destroy the product. Additionally, the flow behavior strongly depends on changing product properties. Hence, they have to be included into the simulation model. To describe important product properties, the following equations are used

$$
\varrho\left(\vartheta, w_{d c}\right)=\underbrace{\left(\mathrm{A}_{\varrho, \mathrm{w}}+\mathrm{B}_{\varrho, \mathrm{w}} \frac{\vartheta}{\mathrm{K}}+\mathrm{C}_{\varrho, \mathrm{w}} \frac{\vartheta^{2}}{\mathrm{~K}^{2}}\right) \frac{\mathrm{kg}}{\mathrm{m}^{3}}}_{=\varrho_{\mathrm{w}}(\vartheta)}\left(1+\mathrm{A}_{\varrho} w_{d c}^{\mathrm{B}}\right),
$$




$$
\begin{aligned}
\Delta h_{v}(\vartheta)= & \mathrm{B}_{h}\left(\frac{1-\frac{\vartheta}{\mathrm{C}_{h}}}{1-\frac{\mathrm{A}_{h}}{\mathrm{C}_{h}}}\right)^{0.38} \frac{\mathrm{kJ}}{\mathrm{kg}}, \\
c_{p}\left(\vartheta, w_{d c}\right)= & \left(\mathrm{A}_{c}+\mathrm{B}_{c} \vartheta\right) w_{d c} \frac{\mathrm{kJ}}{\mathrm{kg} \cdot \mathrm{K}}+\underbrace{\left(\mathrm{A}_{c, \mathrm{w}}+\mathrm{B}_{c, \mathrm{w}} \vartheta+\mathrm{C}_{c, \mathrm{w}} \vartheta^{2}\right) \frac{\mathrm{kJ}}{\mathrm{kg} \cdot \mathrm{K}}}_{=c_{p, \mathrm{w}}(\vartheta)} \\
& \times\left(1-w_{d c}\right), \\
\eta\left(\vartheta, w_{d c}\right)= & \exp \left(\mathrm{E}_{\eta}+\frac{\mathrm{F}_{\eta}}{\mathrm{C}_{\eta} w_{d c}+1}+\mathrm{A}_{\eta} w_{d c}^{\mathrm{D}_{\eta}}\right. \\
& \left.-\left(\mathrm{B}_{\eta} w_{d c}+\mathrm{G}_{\eta}\right)\left(\vartheta-\vartheta_{\mathrm{amb}}\right)\right) \mathrm{Pa} \cdot \mathrm{s} \\
\Delta \vartheta\left(\vartheta, w_{d c}\right)= & \left(\mathrm{A}_{\Delta} w_{d c}{ }^{\mathrm{B}} \Delta+\mathrm{C}_{\Delta} w_{d c} \frac{\vartheta-343.15}{100}\right) \mathrm{K}
\end{aligned}
$$

Here, it is assumed that the considered product properties are mainly affected by the product temperature $\vartheta$ and the dry matter mass fraction $w_{d c}$. Additionally, note that the constants (A, B, C, etc.) are fitted by using data from experiments.

\section{References}

Addison, W.I., Kestner, A.P.V., Limited, S.A., 1981. Large falling film evaporators and vapour compression. In: Proceedings of the South African Sugar Technologists' Association, pp. 56-58.

Andersen, J., Glasson, L., Lees, F., 1961. The control of a single-effect concentrating evaporator. Trans. Soc. Inst. Tech 13 (1), 21.

Andre, H., Ritter, R., 1968. Dynamic response of a double effect evaporator. Can. J. Chem. Eng. 46 (4), 259-264.

Angeletti, S., Moresi, M., 1983. Modelling of multiple-effect falling-film evaporators. Int. J. Food Sci. Technol. 18 (5), 539-563.

Atkins, P., de Paula, J., 2006. Physical Chemistry. W. H. Freeman.

Auinger, H., Ehmann, J., Grütesen, L., Heinrich, J., Huk, M., Jürgens, K., Klein, W., Kuhn, A., Kujawski, B., Metz, D., Muschet, A., Nagel, A., Peters, H., Rölli, R., Schindler, C., Scholl, K., Schwind, M., Seckler, J., Seppendorf, V., Valentin-Rumpel, F., Voß, M., 2018. VDI Richtlinien, VDI 2173: Strömungstechnische Kenngrößen von Stellgeräten und deren Bestimmung. Technical Report. Verein Deutscher Ingenieure. ICS 23.060.40

Bakker, H.H., Marsh, C., Paramalingam, S., Chen, H., 2006. Cascade controller design for concentration control in a falling-film evaporator. Food Control 17, 325-330.

Bojnourd, F.M., Fanaei, M.A., Zohreie, H., 2015. Mathematical modelling and dynamic simulation of multi-effect falling-film evaporator for milk powder production. Math. Comput. Model. Dyn. Syst. 21 (4), 336-358. doi:10.1080/13873954.2014. 980276.

Bolmstedt, U., 1977. Simulation of the steady-state and dynamic behaviour of multiple effect evaporation plants part 2: dynamic behaviour. Comput.-Aided Des. 9 (1), 29-40. doi:10.1016/0010-4485(77)90060-4.

Costa, A.O.S., Lima, E.L., 2003. Modelling and control of an industrial multiple-effect evaporator system. Can. J. Chem. Eng. 81 (5).

Cunningham, P., Canty, N., O’Mahony, T., O'Connor, B., O'Callaghan, D., 2006. System identification of a falling-film evaporator in the dairy industry. In: UK Automatic Control Conference, pp. 1-7.

Daz-Ovalle, C.O., Gonzlez-Alatorre, G., Alvarado, J.F., 2017. Analysis of the dynamic response of falling-film evaporators considering fouling. Food Bioprod. Process. 104, 124-136. doi:10.1016/j.fbp.2017.05.007.

Early, R., 1998. The Technology of Dairy Products, second Blackie Academic and Professional.

GEA Wiegand GmbH, 2016. Evaporation technology. https://www.gea.com/en/ binaries/evaporation-falling-film-forced-circulation-vapor-recompression-gea tcm11-34893.pdf.

Gourdon, M., Innings, F., Jongsma, A., Vamling, L., 2015. Qualitative investigation of the flow behaviour during falling film evaporation of a dairy product. Exp. Therm Fluid Sci. 60, 9-19.

Gourdon, M., Mura, E., 2017. Performance evaluation of falling film evaporators in the dairy industry. Food Bioprod. Process. 101, 22-31.

Haasbroek, A., Steyn, W., Auret, L., 2013. Advanced control with fundamental and data-based modeling for falling film evaporators. In: IEEE International Conference on Industrial Technology, pp. 46-51.
Hirsch, C., 1988. Numerical Computation of Internal and External Flows Volume 1: Fundamentals of Numerical Discretization. John Wiley and Sons, Hoboken, New Jersey.

Hussey, P., 1973. A digital computer model of a multiple effect evaporator. Proc. South Afvican Sugar Technol.' Assoc.-June 7, 1.

Jernqvist, A., Olgard, G., Hedstrom, B., 1966. A digital computer program for multiple effect evaporation. Svensk Papperstidning-Nordisk Cellulosa 69 (15).

Johnson, D., 1960. Simulation and analysis improve evaporator control. ISA J. 7 (7), 46.

Khanam, S., Mohanty, B., 2010. Energy reduction schemes for multiple effect evaporator systems. Appl. Energy 87 (4), 1102-1111. doi:10.1016/j.apenergy.2009.05. 003.

Khanam, S., Mohanty, B., 2011. Development of a new model for multiple effect evaporator system. Comput. Chem. Eng. 35 (10), 1983-1993. doi:10.1016/ j.compchemeng.2010.11.001.

Kharangate, C.R., Lee, H., Mudawar, I., 2015. Computational modeling of turbulent evaporating falling films. Int. J. Heat Mass Transf. 81, 52-62.

Koko, F.W., Joye, D.D., 1987. Design calculations for multiple-effect evaporators. 2. comparison of linear and nonlinear methods. Ind. Eng. Chem. Res. 26 (1), 104107. doi:10.1021/ie00061a020.

Kothare, M.V., Campo, P.J., Morari, M., Nett, C.N., 1994. A unified framework for the study of anti-windup designs. Automatica 30 (12), 1869-1883.

Lvine, J., 2009. Springer doi:10.1007/978-3-642-00839-9.

Munir, M., Zhang, Y., Wilson, D., Yu, W., Young, B., 2014. Modelling of a falling film evaporator for dairy processes. In: Chemeca 2014: Processing excellence; Powering our future. Barton, ACT:Engineers Australia, pp. 174-181.

Newell, R.B., Fisher, D.G., 1972. Model development, reduction, and experimental evaluation for an evaporator. Ind. Eng. Chem. Process Des. Dev. 11 (2), 213-221.

O'Callaghan, D., Cunningham, P., 2005. Modern process control techniques in the production of dried milk products - a review. Lait $85,335-342$.

Padmanaban, A., 2006. Film Thickness Measurements in Falling Annular Films. University of Saskatchewan, Saskatoon.

Paramalingam, S., 2004. Modelling, Optimisation and Control of a Falling-Film Evaporator. Massey University, New Zealand.

Quaak, P., Gerritsen, J., 1990. Modelling dynamic behaviour of multiple-effect falling-film evaporators. Comput. Appl. Chem. Eng.

Quaak, P., van Wijck, M., van Haren, J., 1994. Comparison of process identification and physical modelling for falling-film evaporators. Food Control 5 (2), 73-82. doi:10.1016/0956-7135(94)90089-2.

Ramirez, C., Patel, M., Blok, K., 2006. From fluid milk to milk powder: energy use and energy efficiency in the european dairy industry. Energy 31 (12), 1984-2004.

Ruan, Q., Jiang, H., Nian, M., Yan, Z., 2015. Mathematical modeling and simulation of countercurrent multiple effect evaporation for fruit juice concentration. J. Food Eng 146, 243-251. doi:10.1016/j.jfoodeng.2014.09.015.

Russell, N., Bakker, H., Chaplin, R., 2000. A comparison of dynamic models for an evaporation process. Chem. Eng. Res. Des. 78 (8), 1120-1128. doi:10.1205/ 026387600528274. Separation Processes.

Speight, J.G., 2017. Lange's Handbook of Chemistry, seventeenth McGraw-Hill Education Ltd.

Srivastava, D., Mohanty, B., Bhargava, R., 2013. Modeling and simulation of mee system used in the sugar industry. Chem. Eng. Commun. 200 (8), 1089-1101. doi:10.1080/00986445.2012.737876.

Stefanov, Z., Hoo, K.A., 2005. Control of a multiple-effect falling-film evaporator plant. Ind. Eng. Chem. Res. 44 (9), 3146-3158. doi:10.1021/ie049397w.

Stefanov, Z.I., Hoo, K.A., 2004. Distributed parameter model of black liquor fallingfilm evaporators. 2. modeling of a multiple-effect evaporator plant. Ind. Eng. Chem. Res. 43 (25), 8117-8132. doi:10.1021/ie049611g.

Tonelli, S.M., Romagnoli, J., Porras, J., 1990. Computer package for transient analysis of industrial multiple-effect evaporators. J. Food Eng. 12 (4), 267-281. doi:10. 1016/0260-8774(90)90002-P.

Verein Deutscher Ingenieure, 2005. VDI-Waermeatlas, tenth Springer Berlin Heidelberg, Wiesbaden.

Westerberg, A., Hillenbrand, J., 1988. The synthesis of multiple-effect evaporator systems using minimum utility insightsii. liquid flowpattern selection. Comput. Chem. Eng. 12 (7), 625-636. doi:10.1016/0098-1354(88)80004-8. Special Issue on Process Systems Engineering.

van Wijck, M., Quaak, P., van Haren, J., 1994. Multivariable supervisory control of a four-effect falling-film evaporator. Food Control 5 (2), 83-89. doi:10.1016/ 0956-7135(94)90090-6.

Winchester, J., 2000. Model Based Analysis of the Operation and Control of FallingFilm Evaporators. Massey University, New Zealand.

Winchester, J., Marsh, C., 1999. Dynamics and control of falling film evaporators with mechanical vapour recompression. In: Proceedings of the American Control Conference, pp. 3600-3604.

Zain, O.S., Kumar, S., 1996. Simulation of a multiple effect evaporator for concentrating caustic soda solution-computational aspects. J. Chem. Eng. Jpn. 29 (5), 889-893.

Zhang, F., Yeddanapudi, M. Modeling and simulation of time-varying delays. Mathworks.

Zhang, Y., Munir, M.T., Udugama, I., Yu, W., Young, B.R., 2018. Modelling of a milk powder falling film evaporator for predicting process trends and comparison of energy consumption. J. Food Eng. 225, 26-33. 
Karlsruher Institut für Technologie

\section{Repository KITopen}

Dies ist ein Postprint/begutachtetes Manuskript.

\section{Empfohlene Zitierung:}

Schwaer, C.; Hofmann, J.; Mühlpfordt, M.; Frank, A.; Gröll, L. Modular Simulation Model for Falling Film Evaporators with Novel Approach to Manage Dominant Time-varying Transport Delays. 2020. Computers \& chemical engineering, 132, Article:106604. doi: $10.5445 / / R / 1000099164$

https://publikationen.bibliothek.kit.edu/1000099164

Zitierung der Originalveröffentlichung:

Schwaer, C.; Hofmann, J.; Mühlpfordt, M.; Frank, A.; Gröll, L. Modular Simulation Model for Falling Film Evaporators with Novel Approach to Manage Dominant Time-varying Transport Delays.

2020. Computers \& chemical engineering, 132, Article: 106604. doi:10.1016/j.compchemeng.2019.106604 